\title{
The Usefulness of Fungicide Mixtures and Alternation for Delaying the Selection for Resistance in Populations of Mycosphaerella graminicola on Winter Wheat: A Modeling Analysis
}

\author{
P. H. F. Hobbelen, N. D. Paveley, R. P. Oliver, and F. van den Bosch
}

First and fourth authors: Rothamsted Research, Harpenden, Hertfordshire, AL5 2JQ, United Kingdom; second author: ADAS UK Ltd., High Mowthorpe, Duggleby, Malton, North Yorkshire, YO17 8BP, United Kingdom; and third author: Curtin University, Australian Centre for Necrotrophic Fungal Pathogens, Department of Environment \& Agriculture, Bentley, WA 6845, Australia. Accepted for publication 29 January 2013.

\begin{abstract}
Hobbelen, P. H. F., Paveley, N. D., Oliver, R. P., and van den Bosch, F. 2013. The usefulness of fungicide mixtures and alternation for delaying the selection for resistance in populations of Mycosphaerella graminicola on winter wheat: A modeling analysis. Phytopathology 103:690-707.

A fungicide resistance model (reported and tested previously) was amended to describe the development of resistance in Mycosphaerella graminicola populations in winter wheat (Triticum aestivum) crops in two sets of fields, connected by spore dispersal. The model was used to evaluate the usefulness of concurrent, alternating, or mixture use of two highresistance-risk fungicides as resistance management strategies. We determined the effect on the usefulness of each strategy of (i) fitness costs of

resistance, (ii) partial resistance to fungicides, (iii) differences in the doseresponse curves and decay rates between fungicides, and (iv) different frequencies of the double-resistant strain at the start of a treatment strategy. Parameter values for the quinine outside inhibitor pyraclostrobin were used to represent two fungicides with differing modes of action. The effectiveness of each strategy was quantified as the maximum number of growing seasons that disease was effectively controlled in both sets of fields. For all scenarios, the maximum effective lives achieved by the use of the strategies were in the order mixtures $\geq$ alternation $\geq$ concurrent use. Mixtures were of particular benefit where the pathogen strain resistant to both modes of action incurred a fitness penalty or was present at a low initial frequency.
\end{abstract}

Resistance management strategies aim to delay the evolution and spread of resistant pathogen strains while using fungicide treatments which provide effective disease control. Possible strategies include (i) choice of dose, (ii) constraints on the maximum number of applications per season, (iii) spatial or temporal heterogeneity in the use of fungicides, (iv) mixing of fungicides with different modes of action (MOA), and (v) alternation of fungicides with different MOA $(1,5,34,42)$.

Mixing multi-site-acting and single-site-acting fungicides has been used as a resistance management strategy, because it reduces the selection pressure on the pathogen to evolve resistance to the single-site active substance, which is at higher risk of fungicide resistance development (16). However, there are relatively few multi-site fungicides available. This leads to the question of whether strategies for the application of two single-site-acting fungicides (hereafter referred to as high-risk fungicides) may reduce selection for resistance to one or both fungicides. The possible options for the deployment of two or more fungicides of differing MOA are (i) to mix them (as formulated or tank mixtures); (ii) to alternate their application in the spray program; or (iii) if mixtures or alternations are not used, then a single MOA will be applied to each field but different fields will receive different MOA concurrently.

Although there is considerable experimental literature which determines the effect of mixtures of two high-risk fungicides on the selection for resistance, with a few exceptions $(4,22,45)$ the

Corresponding author: P. H. F. Hobbelen; E-mail address: peter.hobbelen@phe.gov.uk

* The $e$-Xtra logo stands for "electronic extra" and indicates that the online version contains two supplemental tables.

http://dx.doi.org/10.1094/PHYTO-06-12-0142-R

(c) 2013 The American Phytopathological Society development of resistance was only tracked to one of the highrisk fungicides in the mixture $(3,4,8-11,14,17,18,26,28,30,38,40)$. Experimental literature that compares the development of resistance between mixture and alternating use of two high-risk fungicides is scarce $(17,30)$ and resistance development was again only tracked to one high-risk fungicide. To our knowledge, there is no literature on the effect of concurrent use of two high-risk fungicides on the development of resistance. There are a number of modeling studies that determine the usefulness of fungicide mixtures as a resistance management strategy but, in most cases, the mixture partner was a multi-site fungicide (16,19-21,24, $27,32,37)$. One modeling study compared the effects of mixture and sequential use of two high-risk fungicides on the development of resistance (33). Another modeling study compared the effects of mixture and concurrent use of two high-risk fungicides on the development of resistance (2). To our knowledge, there is no modeling study which compares the effect of mixing, alternation, and concurrent use of two high-risk fungicides on the development of resistance. Therefore, the relative usefulness of these resistance management strategies cannot be determined from the current literature.

Hobbelen et al. (15) derived a generic model to describe the development of fungicide resistance in foliar pathogen populations of cereal crops. This model differs from previous fungicide resistance models $(2,33)$ because it describes the seasonal development of the canopy of a crop, which is important for a number of reasons. First, this makes it possible to account for competition for healthy leaf area on the growth of pathogen strains, which is relevant because the development of fungicide resistance may differ between models that assume density-independent or density-dependent growth of pathogen strains (41). Second, accounting for seasonality makes it possible to determine the green canopy area duration, which is an indicator of yield 
(43). This allows the use of a criterion for the usefulness of resistance management strategies, which is relevant to commercial practice: the number of growing seasons during which a treatment strategy provides effective disease control. Third, accounting for seasonality makes it possible to test the model by comparing predictions against independent field data on the frequency of resistance at certain times during a growing season. Hobbelen et al. (15) successfully tested the model by comparing model predictions against independent data for the selection of quinone outside inhibitor (QoI)-resistant strains in powdery mildew (Blumeria graminis f. sp. hordeii) on spring barley (Hordeum vulgare) in response to fungicide applications (15).

This article uses this tested model to compare concurrent, alternating, and mixture use of two high-risk fungicides as a resistance management strategy. We explore whether the effectiveness of each strategy is affected by (i) fitness costs of resistance, (ii) partial resistance to fungicides (where a fungicide can still provide some efficacy against an insensitive strain when applied at or below the maximum permitted dose), (iii) differences in the doseresponse curves and decay rates between fungicides, and (iv) the relative frequency of resistant strains when a treatment strategy is implemented. As a model system, we used Mycosphaerella graminicola (causal organism of Septoria leaf blotch), an economically important disease in wheat-growing areas around the world (36), on winter wheat (Triticum aestivum).

\section{MATERIALS AND METHODS}

Model structure. We adapted the model of Hobbelen et al. (15) to describe selection for resistance in M. graminicola on winter wheat in two sets of fields that may receive different treatments. The two sets of fields are connected through the dispersal of ascospores at the end of growing seasons $(13,35)$. The spatial distribution of the two sets of fields over the landscape is not specified but it is assumed that both occupy equally large areas and that ascospores from both populations mix completely before depositing on plants as inoculum for the next growing season. The part of the model that describes selection for fungicide resistance within each growing season has the same structure for both sets of fields (Fig. 1). In the following equations, superscript $i$ indicates the set of fields with $i \in\{1,2\}$.

Canopy dynamics. The model describes the seasonal growth and senescence of the winter wheat canopy in order to account for the effect of availability of host tissue on the growth of the pathogen population. The model describes the growth of the combined area of leaves 1 to 3 (counting down the mature culm, with leaf 1 being the flag leaf), because these leaves are primarily responsible for yield formation (29) and intercept most of the sprayed fungicides. Leaf area is expressed as leaf area per ground area. Hereafter, we use "upper leaves" to refer to the combined area of leaves 1 to 3 and "density" to refer to leaf area per ground area.

The total leaf area $\left(A^{i}\right)$, which is the sum of healthy, infected, and dead or senesced leaf tissue, grows according to the monomolecular equation (39)

$$
\left(d A^{i} / d t\right)=\gamma\left(A_{\max }-A^{i}\right)
$$

and reaches its maximum density $\left(A_{\max }\right)$ at growth stage (GS) 39 on the Zadoks' scale (44). The growth of the total leaf area of winter wheat is not affected by foliar disease within the range of severities that is realistic in agronomic practice (12).

In the absence of disease, the density of healthy leaf area $\left(H^{i}\right)$ increases until the flag leaf is completely emerged (GS 39), after which it remains constant until senescence starts (GS 61) and subsequently decreases until senescence is complete (GS 87). The density of healthy leaf area in the absence of disease is thus described by

$$
\left(d H^{i} / d t\right)=\gamma\left(A_{\max }-A\right)-\sigma(t) H^{i}
$$

with senescence rate

$$
\sigma(t)=\left\{\begin{array}{cc}
0, & t<t_{G S 61} \\
0.005\left(\frac{t-t_{G S 61}}{t_{G S 87}-t_{G S 61}}\right)+0.1 e^{-0.02\left(t_{G S 87}-t\right)}, & t \geq t_{G S 61}
\end{array}\right.
$$

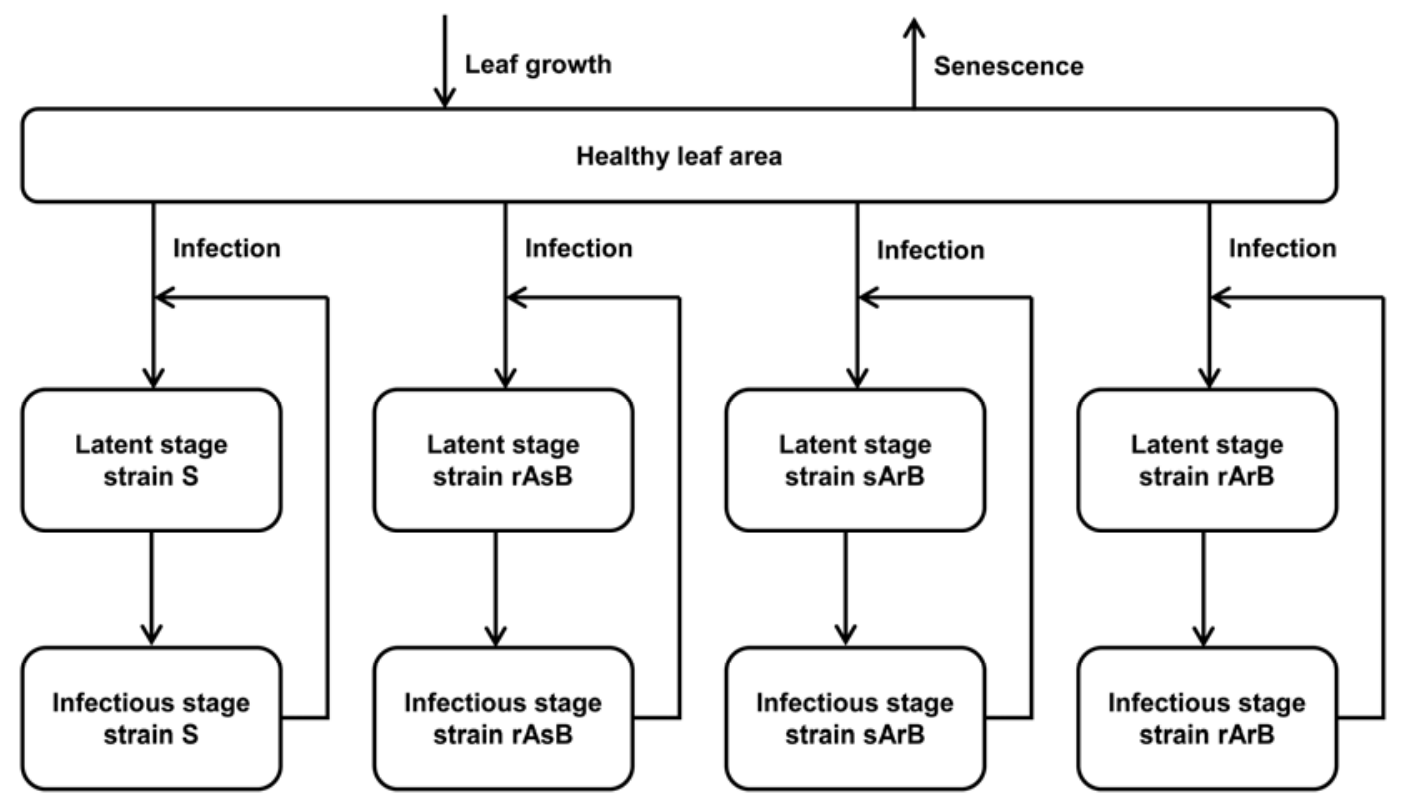

Fig. 1. Structure of the simulation model which describes the growth of the canopy of winter wheat and the growth of the sensitive and resistant pathogen strains on the canopy during a growing season. This structure is the same for set of fields 1 and set of fields 2 . The pathogen populations in both sets of fields are connected by spore dispersal between growing seasons. A and B denote two high-risk fungicides with a different mode of action, which are assumed to reduce the infection efficiency and increase the length of the latent stage of sensitive or partially resistant pathogen strains. Strain S represents the sensitive pathogen strain, strain $\mathrm{rAsB}$ represents the strain (partially) resistant to A and sensitive to B, strain sArB represents the strain sensitive to A and (partially) resistant to B, and strain $\mathrm{rArB}$ represents the strain which is (partially) resistant to both fungicides A and B. Although not shown, the area occupied by latent lesions of all pathogen strains decreases due to senescence and the area occupied by infectious lesions of all pathogen strains decreases due to reaching the end of the infectious period. 
The senescence rate increases exponentially from approximately $0\left(<10^{-7}\right)$ at GS $61\left(t_{G S 61}\right)$ to a maximum value of 0.1 at GS 87. This reduces the healthy leaf area at GS $87\left(t_{G S 87}\right)$ to $<1 \%$ of the maximum leaf area $\left(A_{\max }\right)$, which approximates complete senescence.

The pathogen strains. Referring to the two high-risk fungicides of differing MOA as $\mathrm{A}$ and $\mathrm{B}$, the pathogen population consists of a strain that is sensitive to $\mathrm{A}$ and $\mathrm{B}$, a strain that is resistant to $\mathrm{A}$ and sensitive to $\mathrm{B}$, a strain that is sensitive to $\mathrm{A}$ and resistant to $\mathrm{B}$, and a strain that is resistant to both $\mathrm{A}$ and $\mathrm{B}$. In equations, these strains are indicated by the subscripts $s, A, B$, and $A B$, respectively. The life cycle of each $M$. graminicola strain is divided into a latent stage $\left(L^{i}\right)$ and an infectious stage $\left(I^{i}\right)$. Infected leaf area remains green during the latent stage but dies at the start of the infectious stage, when $M$. graminicola causes necrotic lesions. The duration of the latent period is $1 / \delta$ and the duration of the infectious period is $1 / \mu$.

The development of an epidemic. At the start of the emergence of leaf 3 , the healthy leaf area is infected by spores from lower leaves. The density of infectious lesions on lower leaves $\left(F^{i}\right)$ and, therefore, the spore production rate is assumed to decrease according to the equation

$$
F^{i}=F_{0} e^{-\lambda t}
$$

in which $F_{0}$ is the initial density of infectious lesions on lower leaves at the start of the emergence of leaf 3 and $\lambda$ represents the loss rate of infectious lesions on lower leaves due to reaching the end of their infectious period.

We assume that a fraction $\theta_{A}$ of the infectious lesions on lower leaves consists of the strain resistant to A only, a fraction $\theta_{B}$ consists of the strain resistant to $\mathrm{B}$ only, and a fraction $\theta_{A B}$ consists of the strain resistant to both A and B. At the start of a treatment strategy, initial values are assigned to these fractions. Hereafter, we refer to these values as the "initial frequency" of a strain. The fractions $\theta_{A}, \theta_{B}$, and $\theta_{A B}$ are constant within a growing season, because we assume that most of the sprayed fungicides are intercepted by the upper leaves. The values of these fractions change between growing seasons, however, as a result of selection for resistance, as explained hereafter.

The rate at which an infectious lesion generates new infections, the transmission rate, is determined by the product of (i) the sporulation rate of an infectious lesion; (ii) the probability that spores land on the upper leaves; (iii) the probability that a spore lands on healthy area of leaf tissue, given that it lands on the upper leaves; and (iv) the infection efficiency of spores. Points i, ii, and iv are combined in the compound parameter $\rho$. We account for point iii by multiplying parameter $\rho$ by the fraction of the total area of leaves that consists of healthy leaf tissue, $H^{i} / A^{i}$. This makes the growth of the sensitive and resistant strain dependent on the availability of healthy host tissue. Hereafter, we refer to parameter $\rho$ as the transmission rate.

The epidemic model. These assumptions lead to the following equations describing the density of the healthy leaf area in the presence of disease and the densities of latent and infectious leaf areas of the sensitive and three resistant strains within a set of fields:

$$
\begin{gathered}
\frac{d H^{i}}{d t}=\gamma\left(A_{\max }-A^{i}\right)-\rho_{s}^{i}\left(\frac{H^{i}}{A^{i}}\right)\left(I_{s}^{i}+\left(1-\theta_{A}-\theta_{B}-\theta_{A B}\right) F^{i}\right)-\rho_{A}^{i}\left(\frac{H^{i}}{A^{i}}\right)\left(I_{A}^{i}+\theta_{A} F^{i}\right)- \\
\rho_{B}^{i}\left(\frac{H^{i}}{A^{i}}\right)\left(I_{B}^{i}+\theta_{B} F^{i}\right)-\rho_{A B}^{i}\left(\frac{H^{i}}{A^{i}}\right)\left(I_{A B}^{i}+\theta_{A B} F^{i}\right)-\sigma(t) H^{i} \\
\frac{d L_{s}^{i}}{d t}=\rho_{s}^{i}\left(\frac{H^{i}}{A^{i}}\right)\left(I_{s}^{i}+\left(1-\theta_{A}-\theta_{B}-\theta_{A B}\right) F^{i}\right)-\left(\delta_{s}^{i}+\sigma(t)\right) L_{s}^{i} \\
\frac{d I_{s}^{i}}{d t}=\delta_{s}^{i} L_{s}^{i}-\mu I_{s}^{i}
\end{gathered}
$$

$$
\begin{gathered}
\frac{d L_{A}^{i}}{d t}=\rho_{A}^{i}\left(\frac{H^{i}}{A^{i}}\right)\left(I_{A}^{i}+\theta_{A} F^{i}\right)-\left(\delta_{A}^{i}+\sigma(t)\right) L_{A}^{i} \\
\frac{d I_{A}^{i}}{d t}=\delta_{A}^{i} L_{A}^{i}-\mu I_{A}^{i} \\
\frac{d L_{B}^{i}}{d t}=\rho_{B}^{i}\left(\frac{H^{i}}{A^{i}}\right)\left(I_{B}^{i}+\theta_{B} F^{i}\right)-\left(\delta_{B}^{i}+\sigma(t)\right) L_{B}^{i} \\
\frac{d I_{B}^{i}}{d t}=\delta_{B}^{i} L_{B}^{i}-\mu I_{B}^{i} \\
\frac{d L_{A}^{i}}{d t}=\rho_{A}^{i}\left(\frac{H^{i}}{A^{i}}\right)\left(I_{A}^{i}+\theta_{A} F^{i}\right)-\left(\delta_{A}^{i}+\sigma(t)\right) L_{A}^{i} \\
\frac{d I_{A B}^{i}}{d t}=\delta_{A B}^{i} L_{A B}^{i}-\mu I_{A B}^{i}
\end{gathered}
$$

The dynamics of the pathogen strains between growing seasons. We calculated the resistant fractions of the pathogen population on lower leaves $\left(\theta_{A}, \theta_{B}\right.$, and $\left.\theta_{A B}\right)$ by assuming that (i) ascospores from both sets of fields, which are produced at the end of growing seasons, completely mix before depositing on plants as inoculum for the next growing season; and (ii) both sets of fields have an equal size. The frequency of a strain in the fungal population at the start of a growing season (in both sets of fields) was calculated as a function of the densities of infectious leaf area at the end of the previous growing season $\left(t_{G S 87}\right)$ :

$$
\begin{gathered}
\theta_{A}=\frac{(\vartheta /(1+\vartheta)) I_{A}^{1}\left(t_{G S 87}\right)+(1 /(1+\vartheta)) I_{A}^{2}\left(t_{G S 87}\right)}{I_{t o t}} \\
\theta_{B}=\frac{(\vartheta /(1+\vartheta)) I_{B}^{1}\left(t_{G S 87}\right)+(1 /(1+\vartheta)) I_{B}^{2}\left(t_{G S 87}\right)}{I_{t o t}} \\
\theta_{A B}=\frac{(\vartheta /(1+\vartheta)) I_{A B}^{1}\left(t_{G S 87}\right)+(1 /(1+\vartheta)) I_{A B}^{2}\left(t_{G S 87}\right)}{I_{t o t}} \\
I_{t o t}=(\vartheta /(1+\vartheta))\left(I_{s}^{1}\left(t_{G S 87}\right)+I_{A}^{1}\left(t_{G S 87}\right)+I_{B}^{1}\left(t_{G S 87}\right)+I_{A B}^{1}\left(t_{G S 87}\right)\right)+ \\
(1 /(1+\vartheta))\left(I_{s}^{2}\left(t_{G S 87}\right)+I_{A}^{2}\left(t_{G S 87}\right)+I_{B}^{2}\left(t_{G S 87}\right)+I_{A B}^{2}\left(t_{G S 87}\right)\right)
\end{gathered}
$$

where the superscript indicates the set of fields and the subscript indicates the type of strain. Parameter $\vartheta$ represents the ratio of the area occupied by set of fields 1 and the area occupied by set of fields 2 .

The impact of fitness costs of resistance to fungicides on the pathogen. We assumed that fitness costs of resistance affect the density of strains by decreasing their infection efficiencies (included in $\rho$ ) according to the following functions:

$$
\begin{gathered}
\rho_{A}=\rho\left(1-\omega_{\text {single }}\right) \\
\rho_{B}=\rho\left(1-\omega_{\text {single }}\right) \\
\rho_{A B}=\rho\left(1-\omega_{\text {double }}\right)
\end{gathered}
$$

In these equations, $\rho$ is the transmission rate of the sensitive strain in the absence of fungicides and $\rho_{A}, \rho_{B}$, and $\rho_{A B}$ are the trans- 
mission rates of the resistant strains in the absence of fungicides. Parameter $\omega_{\text {single }}$ is the fraction by which the transmission rate of strains resistant to only one fungicide (A or B) was reduced. Parameter $\omega_{\text {double }}$ is the fraction by which the transmission rate of the double-resistant strain was reduced. If fitness costs were assumed to be present for both single- and double-resistant strains, the reduction of the infection efficiency of the single-resistant strains could be derived from the reduction of the infection efficiency of the double-resistant strain according to the function:

$$
\left(1-\omega_{\text {single }}\right)^{2}=\left(1-\omega_{\text {double }}\right)
$$

The impact of fungicides on the pathogen. We assumed that fungicide treatments affect the density of the pathogen strains by decreasing the infection efficiency (included in $\rho$ ) and increasing the length of the latent period $(1 / \delta)$. This was based on the highrisk fungicides $\mathrm{A}$ and $\mathrm{B}$ representing systemic fungicides with both protectant and eradicant activity (e.g., QoI fungicides) (25). Parameter $\rho$ of the different strains depends on the doses of fungicides $\mathrm{A}$ and $\mathrm{B}$, as described by the functions below:

$$
\begin{gathered}
\rho_{s}^{i}=\rho\left[1-\alpha_{A, s}^{i}\left(C_{A}^{i}\right)\right]\left[1-\alpha_{B, s}^{i}\left(C_{B}^{i}\right)\right] \\
\rho_{A}^{i}=\rho_{A}\left[1-\alpha_{A, r}^{i}\left(C_{A}^{i}\right)\right]\left[1-\alpha_{B, s}^{i}\left(C_{B}^{i}\right)\right] \\
\rho_{B}^{i}=\rho_{B}\left[1-\alpha_{A, s}^{i}\left(C_{A}^{i}\right)\right]\left[1-\alpha_{B, r}^{i}\left(C_{B}^{i}\right)\right] \\
\rho_{A B}^{i}=\rho_{A B}\left[1-\alpha_{A, r}^{i}\left(C_{A}^{i}\right)\right]\left[1-\alpha_{B, r}^{i}\left(C_{B}^{i}\right)\right]
\end{gathered}
$$

The lengths of the latent stage of the different strains depend on the doses of fungicides A and B as described by the functions below:

$$
\begin{aligned}
& 1 / \delta_{s}^{i}=1 /\left(\delta\left[1-\alpha_{A, s}^{i}\left(C_{A}^{i}\right)\right]\left[1-\alpha_{B, s}^{i}\left(C_{B}^{i}\right)\right]\right) \\
& 1 / \delta_{A}^{i}=1 /\left(\delta\left[1-\alpha_{A, r}^{i}\left(C_{A}^{i}\right)\right]\left[1-\alpha_{B, s}^{i}\left(C_{B}^{i}\right)\right]\right) \\
& 1 / \delta_{B}^{i}=1 /\left(\delta\left[1-\alpha_{A, s}^{i}\left(C_{A}^{i}\right)\right]\left[1-\alpha_{B, r}^{i}\left(C_{B}^{i}\right)\right]\right) \\
& 1 / \delta_{A B}^{i}=1 /\left(\delta\left[1-\alpha_{A, r}^{i}\left(C_{A}^{i}\right)\right]\left[1-\alpha_{B, r}^{i}\left(C_{B}^{i}\right)\right]\right)
\end{aligned}
$$

In these equations, the reductions of infection efficiency (included in $\rho$ ) and the development rate of the latent stage $(\delta$ ) by fungicides $\mathrm{A}$ and $\mathrm{B}$ depend on the sensitivity of a fungal strain to these fungicides. The terms $\alpha_{A, s}^{i}\left(C_{A}^{i}\right)$ and $\alpha_{A, r}^{i}\left(C_{A}^{i}\right)$ represent the reduction of these parameters for strains that are completely sensitive or partially resistant to fungicide $\mathrm{A}$, respectively, when fungicide $\mathrm{B}$ is absent or not effective due to resistance. The terms $\alpha_{B, s}^{i}\left(C_{B}^{i}\right)$ and $\alpha_{B, r}^{i}\left(C_{B}^{i}\right)$ represent the reduction of these parameters for strains that are completely sensitive or partially resistant to fungicide $\mathrm{B}$, respectively, when fungicide $\mathrm{A}$ is absent or not effective due to resistance. When strains are completely resistant to fungicide A, the term $\alpha_{A, r}^{i}\left(C_{A}^{i}\right)$ equals zero. Similarly, when strains are completely resistant to fungicide $\mathrm{B}$, the term $\alpha_{B, r}^{i}\left(C_{B}^{i}\right)$ equals zero. We assumed that fungicides $\mathrm{A}$ and $\mathrm{B}$ act independently and, therefore, we multiplied the proportional effect of both fungicides on the life-cycle parameters of the fungal strains (23) when both were present in the same leaf tissue at the same time.
Varying asymptote
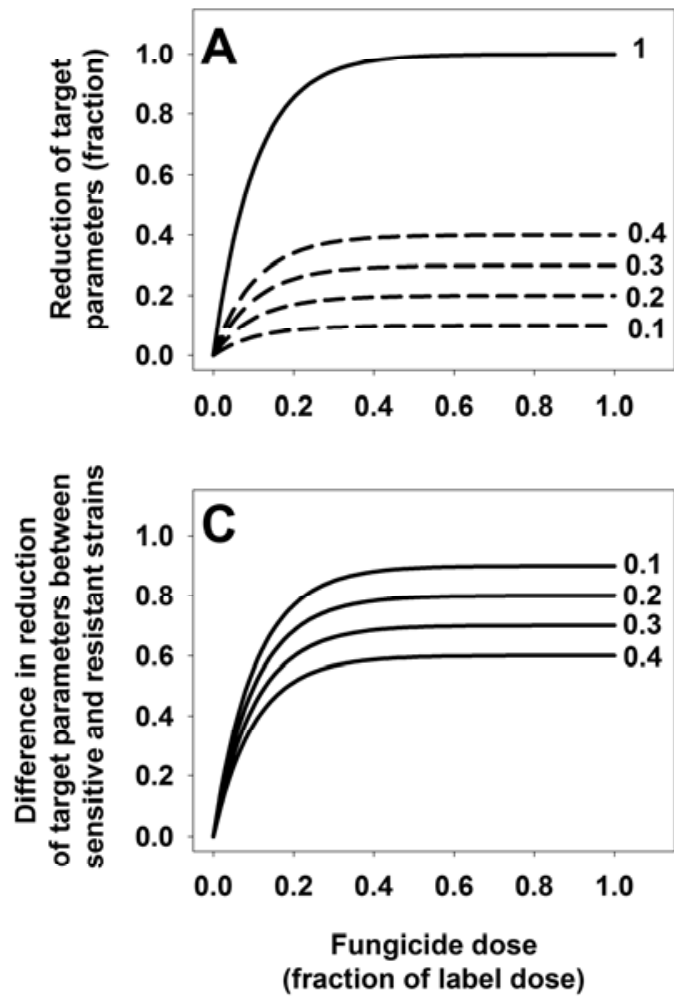

Varying curvature
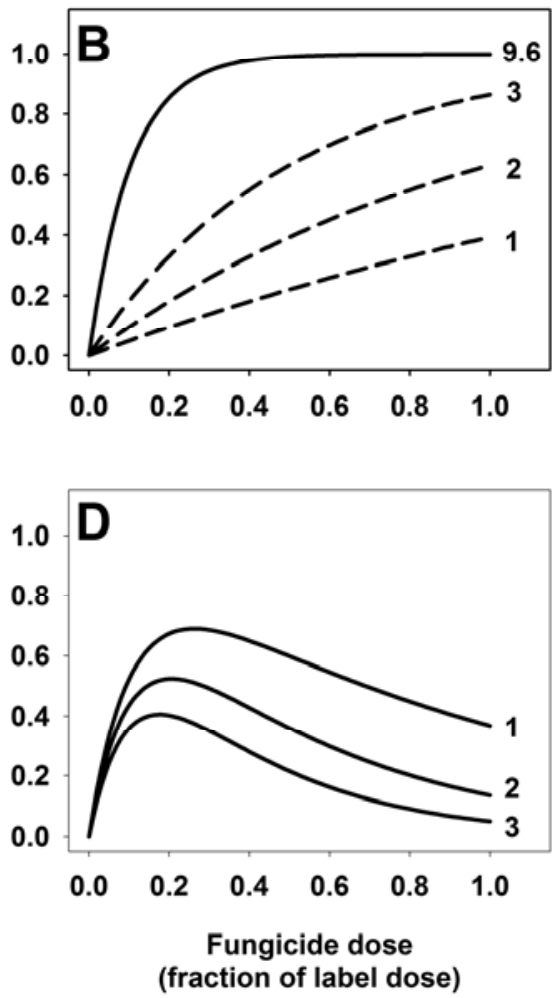

Fig. 2. A and B, Reduction of the life-cycle parameters of the sensitive and partially resistant pathogen strains as a function of the fungicide dose, when partial resistance is modeled by changing $\mathbf{A}$, the asymptote or $\mathbf{B}$, the curvature of the dose-response curve. $\mathbf{C}$ and $\mathbf{D}$, Difference in the reduction of the life-cycle parameters between the sensitive and partially resistant strains as a function of the fungicide dose, when partial resistance is modeled by changing $\mathbf{C}$, the asymptote or $\mathbf{D}$, the curvature of the dose-response curve. Solid lines in graphs A and B represent the sensitive strain and dashed lines represent partially resistant strains. Numbers in graph A denote the value of the asymptote for each line and numbers in graph B denote the value of the curvature parameter for each line. Line labels in graph $\mathrm{C}$ correspond to the values of the asymptotes of the dose-response curves of the partially resistant strains and line labels in graph $\mathrm{D}$ correspond to the values of the curvature parameters of the dose-response curves of the partially resistant strains. 
Dose-response curves. The fractions $\alpha_{A, s}^{i}\left(C_{A}^{i}\right)$ and $\alpha_{B, s}^{i}\left(C_{B}^{i}\right)$, by which the life-cycle parameters of sensitive strains are reduced by fungicides, depend on the fungicide dose according to the functions (Fig. 2):

$$
\begin{aligned}
& \alpha_{A, S}^{i}\left(C_{A}^{i}\right)=\alpha_{A, \max , s}\left(1-\mathrm{e}^{-\beta_{A, S} C_{A}^{i}}\right) \\
& \alpha_{B, s}^{i}\left(C_{B}^{i}\right)=\alpha_{B, \max , s}\left(1-\mathrm{e}^{-\beta_{B, S} C^{i} B}\right)
\end{aligned}
$$

In these equations, parameters $\alpha_{A, \max , s}$ and $\alpha_{B, \max , s}$ represent the maximum reduction of the target parameters for fungicide $\mathrm{A}$ and $\mathrm{B}$, respectively. Parameters $\beta_{A, s}$ and $\beta_{B, s}$ determine the curvature of the dose-response curves.

We accounted for the reduced impact of fungicides on partially resistant strains by decreasing either the maximum reduction of target parameters by fungicides or the curvature of the doseresponse curves for sensitive strains (Fig. 2). The fractions by which the life-cycle parameters of partially resistant strains are reduced, $\alpha_{A, r}^{i}\left(C_{A}^{i}\right)$ and $\alpha_{B, r}^{i}\left(C_{B}^{i}\right)$, depend on the fungicide doses according to the functions:

$$
\begin{aligned}
& \alpha_{A, r}^{i}\left(C_{A}^{i}\right)=\alpha_{A, \max , r}\left(1-\mathrm{e}^{-\beta_{A, r} C_{A}^{i}}\right) \\
& \alpha_{B, r}^{i}\left(C_{B}^{i}\right)=\alpha_{B, \max , r}\left(1-\mathrm{e}^{-\beta_{B, r} C_{B}^{i}}\right)
\end{aligned}
$$

In these equations, parameters $\alpha_{A, \max , r}$ and $\alpha_{B, \max , r}$ represent the maximum reduction of the target parameters by fungicides $\mathrm{A}$ and $\mathrm{B}$, respectively, for partially resistant strains. Parameters $\beta_{A, r}$ and $\beta_{B, r}$ determine the curvature of the dose-response curves $=$ for partially resistant strains. When $\alpha_{A, \max , r}=0$ or $\beta_{A, r}=0$, the reduction of the target parameters by fungicide $\mathrm{A}\left(\alpha_{A, r}^{i}\left(C_{A}^{i}\right)\right)$ is zero and resistance to fungicide $\mathrm{A}$ is complete. When $\alpha_{B, \max , r}=0$ or $\beta_{B, r}=$ 0 , the reduction of the target parameters by fungicide $\mathrm{B}$ $\left(\alpha_{B, r}^{i}\left(C_{B}^{i}\right)\right)$ is zero and resistance to fungicide $\mathrm{B}$ is complete.

\begin{tabular}{|c|c|c|c|}
\hline Parameters $^{\mathrm{a}}$ & Definition & Value $^{b}$ & Dimension $^{\mathrm{c}}$ \\
\hline \multicolumn{4}{|l|}{ Growing area } \\
\hline & Ratio of the area occupied by set of fields 1 and set of fields 2 & 1 & - \\
\hline \multicolumn{4}{|c|}{ (2) } \\
\hline$A_{\max }$ & Maximum density of leaf area & 4.1 & Area \\
\hline$\sigma$ & Senescence rate & Equation 3 & $t^{-1}$ \\
\hline \multicolumn{4}{|l|}{ Pathogen strains } \\
\hline \multicolumn{4}{|l|}{ All } \\
\hline$\lambda$ & Rate at which the density of infectious lesions on lower leaves $\left(F^{i}\right)$ decreases & $8.5 \times 10^{-3}$ & $t^{-1}$ \\
\hline $1 / \delta$ & Length of the latent stage in the absence of fungicides & 266 & $t$ \\
\hline $1 / \mu$ & Length of the infectious stage & 456 & $t$ \\
\hline \multicolumn{4}{|c|}{ Length or the intectious stage } \\
\hline$\rho, \rho_{s}^{i}$ & Transmission rate in the absence and presence of fungicides $\mathrm{e}$ & $2.08 \times 10^{-2}$, Equation 22 & $t^{-1}$ \\
\hline $1 / \delta^{i}{ }_{s}$ & Length of the latent stage in the presence of fungicides & Equation 26 & $t$ \\
\hline \multicolumn{4}{|c|}{ Sensitive to A, resistant to B } \\
\hline$\rho_{A}, \rho_{A}^{i}$ & Transmission rate in the absence and presence of fungicides ${ }^{\mathrm{e}}$ & Equations 18 and 23 & $t^{-1}$ \\
\hline $1 / \delta_{A}^{i}$ & Length of the latent stage in the presence of fungicides & Equation 27 & $t$ \\
\hline \multicolumn{4}{|c|}{ Resistant to both A and B } \\
\hline$\theta_{A B, 0}, \theta_{A B}$ & Frequency at the start of the first and later growing seasons & Variable ${ }^{\mathrm{f}}$, equation 16 & - \\
\hline$\rho_{A B, O}, \rho_{A B}^{i}$ & Transmission rate in the absence and presence of fungicides ${ }^{\mathrm{e}}$ & Equations 20 and 25 & $t^{-1}$ \\
\hline $1 / \delta_{A B}^{i}$ & Length of the latent stage in the presence of fungicides & Equation 29 & $t$ \\
\hline \multicolumn{4}{|c|}{ Fitness costs of resistance } \\
\hline$\omega_{\text {single }}$ & Fraction by the infection efficiency of a single-resistant strain is reduced & Variableg ${ }^{g}$ & - \\
\hline$\omega_{\text {double }}$ & Fraction by which the infection efficiency of the double-resistant strain is reduced & Variable ${ }^{\mathrm{g}}$ & - \\
\hline \multicolumn{4}{|c|}{ Dose-response, decay rate ${ }^{\mathrm{h}}$} \\
\hline$\alpha_{A s,}^{i} \alpha_{B S}^{i}$ & Reduction of the target parameters of the sensitive strain by fungicides $\mathrm{A}$ and $\mathrm{B}$ & Equations 30 and 31 & - \\
\hline$\alpha_{A, r}^{i}, \alpha_{B, r}^{i}$ & Reduction of the target parameters of the resistant strains by fungicides A and B & Equations 32 and 33 & - \\
\hline$\alpha_{A \max s}, \alpha_{B \max s}$ & Maximum reduction of the target parameters of the sensitive strain by fungicides A and B & 1 & - \\
\hline \multicolumn{4}{|c|}{ t may differ between treatment areas have a superscript $i$, which indicates the treatment area $(i=1$ or 2$)$. Pathogen strains were resistant or } \\
\hline \multicolumn{4}{|c|}{ b Parameter values were taken from Hobbelen et al. (16). } \\
\hline \multicolumn{4}{|c|}{ c Symbols: - represents dimensionless, $t$ represents degree-days, area = leaf area per ground area. } \\
\hline \multicolumn{4}{|c|}{$\begin{array}{l}\mathrm{d} \\
\mathrm{d} \\
\text { Lower leaves are leaves that emerged before leaf } 3 \text {, when counting down from the flag leaf (leaf } 1) \text {. }\end{array}$} \\
\hline \multicolumn{4}{|c|}{ e A compound parameter. Described in text. } \\
\hline \multirow{2}{*}{\multicolumn{4}{|c|}{$\begin{array}{l}\mathrm{f} \text { Frequency of the double-resistant strain at the start of a treatment strategy was varied from } 10^{-15} \text { to } 10^{-5} \text { (described in text). } \\
\mathrm{g} \text { See Table } 2 \text {. }\end{array}$}} \\
\hline & & & \\
\hline 2. & ate para & & \\
\hline
\end{tabular}

The decay of fungicides. The decay of the concentrations of fungicide $\mathrm{A}\left(C_{A}^{i}\right)$ and $\mathrm{B}\left(C_{B}^{i}\right)$ (or any active metabolites) was

TABLE 1. Definitions, values, and dimensions of model parameters 
modeled as

$$
\left(d C^{i}{ }_{A} / d t\right)=-v_{A} C_{A}^{i}
$$

$$
\left(d C^{i}{ }_{B} / d t\right)=-v_{B} C_{B}^{i}
$$

with decay rates $v_{A}$ and $v_{B}$ for fungicides $A$ and $B$, respectively. The decay rates can be calculated from the half-life time of fungicides $\mathrm{A}\left(t_{A}\right)$ and $\mathrm{B}\left(t_{B}\right)$ as

$$
\begin{aligned}
& v_{A}=[-\ln (0.5)] / t_{A} \\
& v_{B}=[-\ln (0.5)] / t_{B}
\end{aligned}
$$

A degree-day scale, with a base temperature of $0^{\circ} \mathrm{C}$, was used to incorporate effects of temperature on the growth of the host and the pathogen.
Parameter estimation. The values, dimensions, and definitions of model parameters are summarized in Table 1. The fungicide resistance model that we built upon in this article (15) was parameterized for $M$. graminicola on winter wheat by Hobbelen et al. (16). The notation and values of the model parameters that describe the growth and senescence of the winter wheat canopy and the life-cycle parameters of the sensitive and resistant $M$. graminicola strains were taken from that article. The dose-response curve and decay rate of high-risk fungicide A was estimated from data on the efficacy of the high-risk QoI fungicide pyraclostrobin, as described by Hobbelen et al. (16). The values of parameters that determine the fitness costs of resistance $\left(\omega_{\text {single }}\right.$ and $\left.\omega_{\text {double }}\right)$, the level of resistance to a fungicide $\left(\alpha_{A, \max , r}, \beta_{A, r}\right.$, $\alpha_{B, \max , r}$, and $\beta_{B, r}$ ), and the efficacy of fungicide $\mathrm{B}$ for the sensitive strain $\left(\beta_{A, s}\right.$ and $\left.v_{B}\right)$ differ between the simulated scenarios, which are described below in the Simulations section. The values of these parameters for each scenario are given in Table 2 .

Criterion for the usefulness of a resistance management strategy. The usefulness of a resistance management strategy was

TABLE 2. Overview of the parameters values for all scenarios for which the usefulness of resistance management strategies was evaluated ${ }^{\mathrm{a}}$

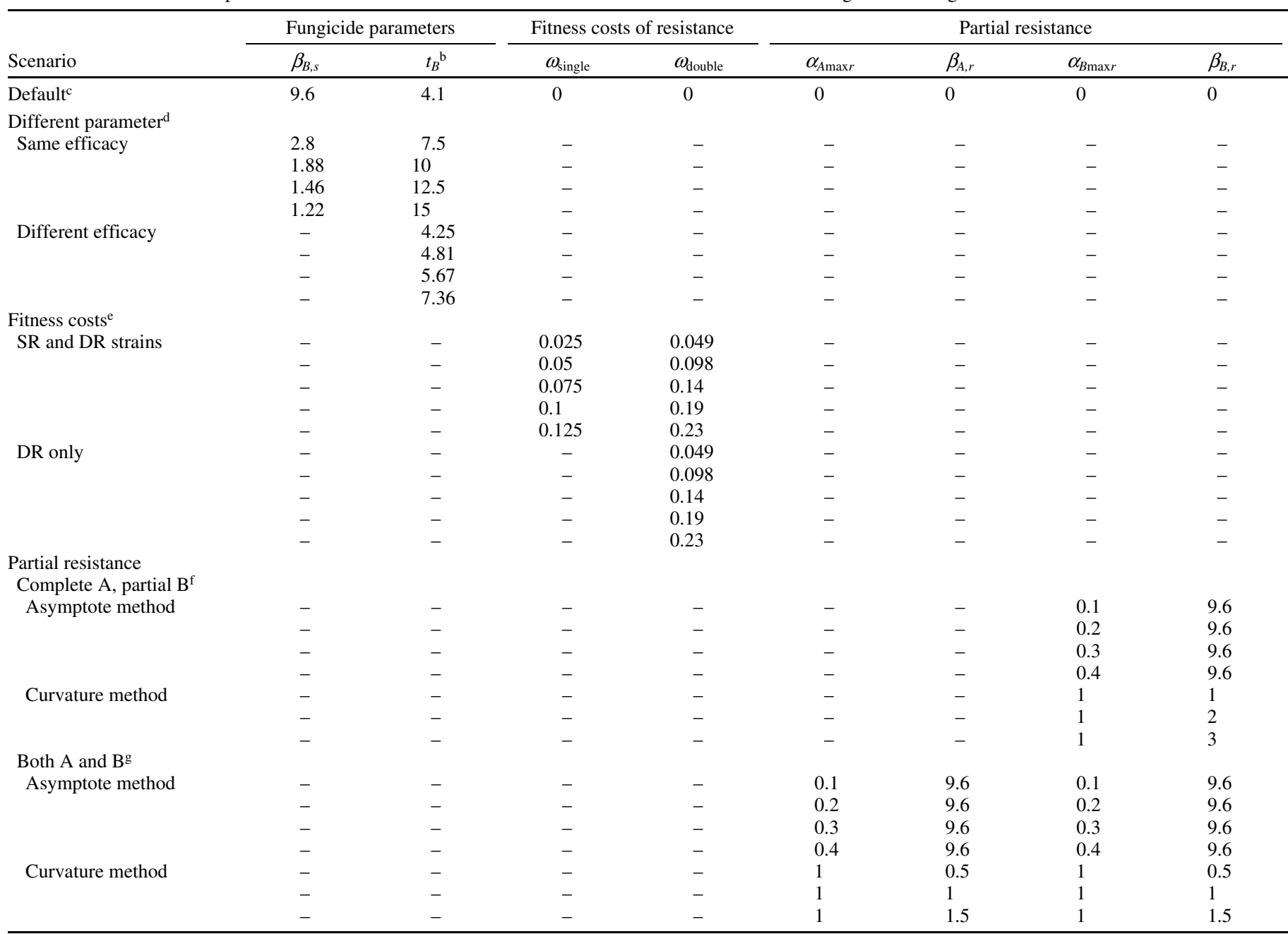

a Definitions and dimensions of the parameter values are shown in Table 1.

${ }^{\mathrm{b}}$ In the model, the half-life time is converted to a degree-day scale by multiplication with $15.2(15)$ and subsequently converted to a decay rate using equation 37 .

c All parameter values are shown for the default scenario, in which (i) the fungicides have identical parameters (but independent mode of action), (ii) there are no fitness costs of resistance, and (iii) resistance to fungicides is complete. For the other scenarios, parameter values are not shown if they are the same as in the default scenario (indicated by - ).

d Fungicides have different parameter values, with the same or different efficacy.

e Fitness costs of resistance for the single-resistant (SR) and double-resistant (DR) strains and for the DR strain only.

${ }^{\mathrm{f}}$ Complete resistance to fungicide A, partial resistance to fungicide B. Asymptote method: the first column gives the maximum reduction of the life-cycle parameters of partially resistant strains by fungicides. Curvature method: the first column gives the curvature parameter of the dose-response curves of the partially resistant strains.

g Partial resistance to both fungicides A and B. 
quantified as the number of years that a strategy can provide "effective" disease control in both sets of fields. Hereafter, we refer to this period as the "effective life" of a resistance management strategy. Disease control was considered to be effective when the disease-induced loss of the healthy area duration (HAD) during the yield forming period was $\leq 5 \%$. Waggoner and Berger (43) defined healthy area as the green leaf area available for photosynthesis, which also includes latent leaf area in the case of M. graminicola. We calculated the HAD as the sum of the areas under the density of the healthy and latent leaf area curves from anthesis (GS 61) to the end of grain filling (GS 87). The effect of disease on the yield of winter wheat is approximately proportional to the HAD over this period $(6,43)$. In order to calculate the effect of disease on HAD on a time scale of days, we calculated the number of accumulated degree-days from GS 61 to GS 87 using data on the average pattern in daily temperatures in Cambridgeshire in the United Kingdom (where the cultivation of wheat dominates the arable land area) during the years 1984 to 2003 (Met Office, United Kingdom).

Selection ratio. To quantify differences in selection between resistance management strategies, we determined the selection pressure that a strategy exerts on the resistant strains by calculating selection ratios (SRs) (15) according to the equation

$$
S R=f_{\text {start season } i+1} / f_{\text {start season } i}
$$

in which $f_{\text {start season } i}$ and $f_{\text {start season } i+1}$ stand for the frequency of the resistant strain in the pathogen population at the start of season $i$ and season $i+1$, respectively. Because we assume that spores from both sets of fields mix at the start of a growing season, the $\mathrm{SR}$ is the same for both sets of fields. Thus, the SR is the factor by which the frequency of the resistant strain is multiplied over one growing season in both sets of fields.

Simulations. We compared the usefulness of five strategies for the application of two high-risk fungicides: concurrent use, mixture use, and three different sequences of alternation. The spray programs in the two sets of fields that correspond to each strategy are shown in Table 3. All simulated spray programs consisted of two sprays per season. The first and second spray were applied at the full emergence of leaf 3 (approximately GS 32) and leaf 1 (GS 39), respectively.

The maximum effective life of a resistance management strategy. The doses of fungicide A or B that were applied per spray time were varied from 0 to $100 \%$ of the maximum permitted dose per application, with intervals of $10 \%$ (11 possible dose rates per

TABLE 3. Two-spray programs for concurrent, alternating, and mixture use of two high-risk fungicides A and B

\begin{tabular}{lcc}
\hline & \multicolumn{2}{c}{ Fungicide applied at $^{\mathrm{a}}$} \\
\cline { 2 - 3 } & First spray & Second spray $^{-}$ \\
\hline Concurrent use & A & A \\
Set of fields 1 & B & B \\
Set of fields 2 & & \\
Alternation AB-AB & A & B \\
Set of fields 1 & A & B \\
Set of fields 2 & B & A \\
Alternation BA-BA & B & A \\
Set of fields 1 & & \\
Set of fields 2 & A & B \\
Alternation AB-BA & B & A \\
Set of fields 1 & & \\
Set of fields 2 & A+B & A+B \\
Mixture use & A+B & A+B \\
Set of fields 1 & Set of fields 2 &
\end{tabular}

${ }^{a}$ First spray was applied at full emergence of leaf 3 (growth stage, GS 32) and the second was applied at full emergence of leaf 1 (GS 39), when counting down from the flag leaf (designated leaf 1 ). fungicide). The effective life of a strategy was determined for all $11 \times 11=121$ possible combinations of dose rates of fungicide $\mathrm{A}$ and $\mathrm{B}$. The dose rates of fungicides were kept constant during the effective life.

The severity of a $M$. graminicola epidemic in the absence of fungicides was assumed to be the same in each growing season. In reality, a number of consecutive years with epidemics similar to the average are likely to be followed by a year with a severe epidemic. In the absence of reliable disease forecasts, growers tend to apply fungicide doses high enough to control a severe epidemic in every growing season in order to be risk averse. To account for this, we determined the effective life of a strategy for each combination of dose rates of fungicide A and B in two ways: first, assuming an average epidemic in the absence of fungicides in all growing seasons; and, second, assuming a severe epidemic in the absence of fungicides in all growing seasons. The maximum effective life of a resistance management strategy was then defined as the highest effective life obtained by using dose rates of fungicide A and B that were able to control a severe epidemic, when the epidemic in the absence of fungicides is average in each growing season.

The average epidemic in the model in the absence of fungicides is representative of an average $M$. graminicola epidemic in the United Kingdom (16). To simulate a severe epidemic, we multiplied the transmission rate of all strains by a factor of 1.2. In the absence of fungicides, this resulted in a maximum percentage of infectious leaf area of $30 \%$ and a HAD-loss of $41 \%$ compared with 23 and $28 \%$ for an average epidemic, respectively.

The default scenario. We first determined the maximum effective life of the resistance management strategies for the simplest case, where (i) fungicides $\mathrm{A}$ and $\mathrm{B}$ have the same dose-response curve and decay rate, (ii) fitness costs of resistance are absent, and (iii) resistance to fungicides is complete. All other scenarios below are derived from this default scenario by introducing differences between fungicide $\mathrm{A}$ and $\mathrm{B}$, introducing fitness costs of resistance, or changing the level of resistance to fungicides (Table 2).

The effect of differences between fungicide $A$ and $B$ on the maximum effective life of strategies. We determined the effect of differences in the dose-response curves and decay rates between fungicides $\mathrm{A}$ and $\mathrm{B}$ on the maximum effective life of the resistance management strategies for two scenarios. In the first scenario, the dose-response curve and half-life time of fungicide $\mathrm{B}$ were varied such that the efficacies of fungicide $A$ and $B$ remained similar. The efficacy of a fungicide was defined as the percent loss of HAD caused by an average epidemic of a completely sensitive population of $M$. graminicola treated with the maximum permitted dose rate of a fungicide. In the second scenario, the half-life time of fungicide $\mathrm{B}$ was varied to change the efficacy of fungicide $\mathrm{B}$ compared with fungicide $\mathrm{A}$.

The effect of fitness costs of resistance on the maximum effective life of strategies. We determined the effect of fitness costs of resistance on the maximum effective life of strategies for two scenarios. In the first scenario, only the fitness of the double-resistant strain was reduced $\left(\omega_{\text {single }}=0, \omega_{\text {double }}>0\right)$. In the second scenario, the fitness of all resistant strains was reduced $\left(\omega_{\text {single }}>0\right.$, $\omega_{\text {double }}>0$ ).

The effect of the level of resistance to fungicides on the maximum effective life of strategies. We determined the effect of the level of resistance to fungicides on the maximum effective life for two scenarios. In the first scenario, the level of partial resistance to fungicide $\mathrm{B}$ was varied but resistance to fungicide $\mathrm{A}$ was complete. In the second scenario, the level of partial resistance to both fungicides was varied equally for both fungicides. For each scenario, we determined the maximum effective lives of the resistance management strategies for two methods of modeling partial resistance (Fig. 2). In the first method, a dose-response curve of a partially resistant strain (equations 32 and 33) was derived from a 
corresponding dose-response curve of the sensitive strain (equations 30 and 31) by decreasing the asymptote of the dose-response curve of the sensitive strain $\left(\alpha_{A, \max , s}\right.$ and $\alpha_{B, \max , s}$ were reduced to $\alpha_{A, \max , r}$ and $\alpha_{B, \max , r}$, respectively). In the second method, a dose-response curve of a partially resistant strain was derived from the corresponding dose-response curve of the sensitive strain by decreasing the curvature of the dose-response curve of the sensitive strain $\left(\beta_{A, \max , s}\right.$ and $\beta_{B, \max , s}$ were reduced to $\beta_{A, \max , r}$ and $\beta_{B, \max , r}$, respectively).

The effect of the initial frequency of resistant strains on the maximum effective life of strategies. At the start of a treatment strategy, the frequency of the double-resistant strain $\left(\theta_{A B}\right)$ relative to the frequency of the single-resistant strains $\left(\theta_{A}\right.$ and $\left.\theta_{B}\right)$ may vary. The effect of variation in the initial frequencies of the single- and double-resistant strains relative to each other on the maximum effective life for all the scenarios described above was determined for initial frequencies of the double-resistant strain, amounting to $10^{-15}, 10^{-10}$, and $10^{-5}$. In all cases, the initial frequency of both single-resistant strains was $10^{-5}$.

\section{RESULTS}

Within a growing season, concurrent use selected for a singleresistant strain in one set of fields and slightly reduced the frequency of that strain in the other set of fields (Fig. 3). Mixing of spores between seasons equilibrated the strains across the fields prior to the start of each season. Concurrent use selected for the double-resistant strain in both sets of fields (Fig. 3). The mixing

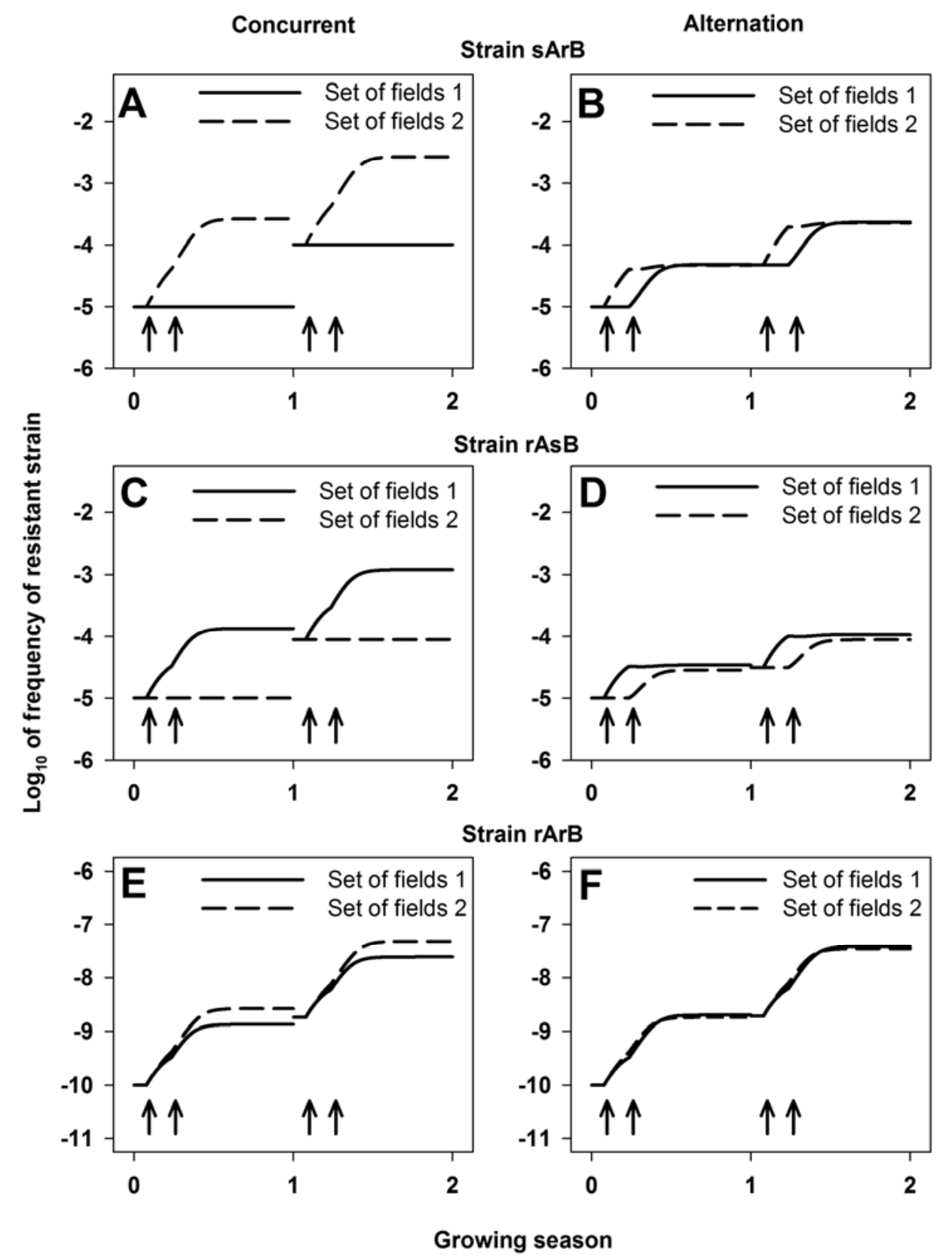

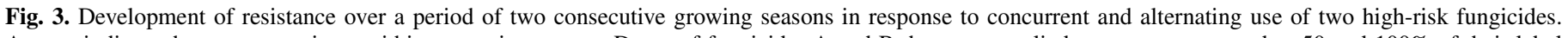

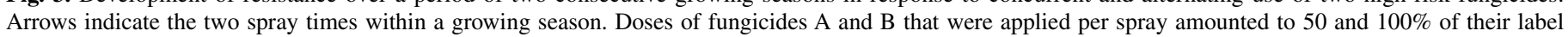

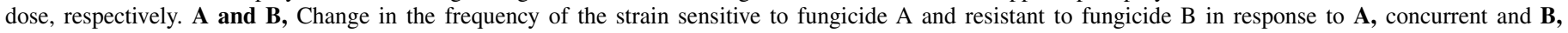

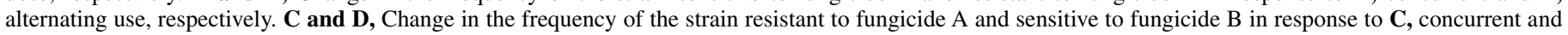

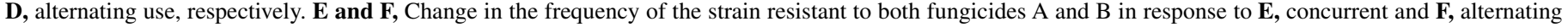

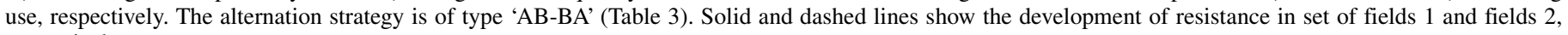
respectively. 
of spores in between seasons increased or decreased the frequency of the double-resistant strain in the set of fields with the lowest or highest selection pressure for resistance, respectively.

The mixture strategy and all alternation strategies selected for the two single-resistant strains and the double-resistant strain in both sets of fields, because fungicides $\mathrm{A}$ and $\mathrm{B}$ were applied in each set of fields. For mixture use and alternation strategies AB$\mathrm{AB}$ and BA-BA, mixing of spores in between growing seasons did not affect the development of resistance, because the spray programs were the same in both sets of fields. For alternation strategy AB-BA, the set of fields with the highest selection pressure for a resistant strain depended on the fungicide doses, the dose-response curve, and decay rate of the fungicides.

The effective lives of the resistance management strategies for all combinations of the doses of fungicides A and B are shown in Table 4 for the default scenario, with an initial frequency of the double-resistant strain of $10^{-10}$. For this scenario, the maximum effective lives of the mixture and alternation strategies were the same and higher, respectively, than the maximum effective life of the concurrent use strategy. When the initial frequency of the double-resistant strain was reduced from $10^{-10}$ to $10^{-15}$, the maximum effective life of both the mixture and the alternation strategy increased, while the maximum effective life of the concurrent use strategy did not change (Fig. 4). The maximum effective life of the mixture strategy increased most and became higher than the maximum effective life of the alternation strategy. When the initial frequency of the double-resistant strain was increased from $10^{-10}$ to $10^{-5}$, the maximum effective life of all resistance management strategies decreased and became similar (Fig. 4). As the relative performance of the strategies varied with the initial frequency for all scenarios considered below, we determined maximum effective lives for initial frequencies of the double-resistant strain of $10^{-5}, 10^{-10}$, and $10^{-15}$.

The effect of differences in the dose-response curve and decay rates between the two fungicides. Decreasing the decay rate and curvature parameter of the dose-response curve of fungicide $\mathrm{B}$, such that the efficacies of fungicides A and B remained the same, did not change the maximum effective life of resistance manage-

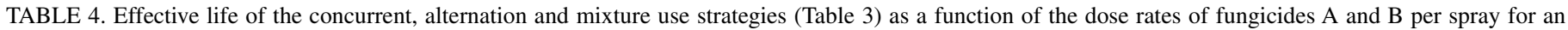
average epidemic of Mycosphaerella graminicola

\begin{tabular}{|c|c|c|c|c|c|c|c|c|c|c|c|}
\hline \multirow[b]{2}{*}{ Dose rate of $\mathrm{B}^{\mathrm{a}}$} & \multicolumn{11}{|c|}{ Dose rate of $\mathrm{A}^{\mathrm{a}}$} \\
\hline & 0 & 0.1 & 0.2 & 0.3 & 0.4 & 0.5 & 0.6 & 0.7 & 0.8 & 0.9 & 1.0 \\
\hline \multicolumn{12}{|l|}{ Concurrent use ${ }^{b}$} \\
\hline 0 & 0 & 0 & 0 & 0 & 0 & 0 & 0 & 0 & 0 & 0 & 0 \\
\hline 0.1 & 0 & 0 & 0 & 0 & 0 & 0 & 0 & 0 & 0 & 0 & 0 \\
\hline 0.2 & 0 & 0 & 0 & 0 & 0 & 0 & 0 & 0 & 0 & 0 & 0 \\
\hline 0.3 & 0 & 0 & 0 & 0 & 0 & 0 & 0 & 0 & 0 & 0 & 0 \\
\hline 0.4 & 0 & 0 & 0 & 0 & 0 & 0 & 0 & 0 & 0 & 0 & 0 \\
\hline 0.5 & 0 & 0 & 0 & 0 & 0 & 4 & 4 & 4 & 4 & 4 & 4 \\
\hline 0.6 & 0 & 0 & 0 & 0 & 0 & 4 & 4 & 4 & 4 & 4 & 4 \\
\hline 0.7 & 0 & 0 & 0 & 0 & 0 & 4 & 4 & 4 & 4 & 4 & 4 \\
\hline 0.8 & 0 & 0 & 0 & 0 & 0 & 4 & 4 & 4 & $4^{c}$ & $4^{c}$ & $4^{c}$ \\
\hline 0.9 & 0 & 0 & 0 & 0 & 0 & 4 & 4 & 4 & $4^{c}$ & $4^{c}$ & $4^{c}$ \\
\hline 1.0 & 0 & 0 & 0 & 0 & 0 & 4 & 4 & 4 & $4^{c}$ & $4^{c}$ & $4^{c}$ \\
\hline \multicolumn{12}{|l|}{ Alternation ${ }^{\mathrm{b}, \mathrm{d}}$} \\
\hline 0 & 0 & 0 & 0 & 0 & 0 & 0 & 0 & 0 & 0 & 0 & 0 \\
\hline 0.1 & 0 & 0 & 0 & 0 & 0 & 0 & 0 & 0 & 0 & 0 & 0 \\
\hline 0.2 & 0 & 0 & 0 & 0 & 0 & 0 & 0 & 0 & 5 & 5 & 5 \\
\hline 0.3 & 0 & 0 & 0 & 0 & 0 & 0 & 6 & 6 & 6 & 6 & 6 \\
\hline 0.4 & 0 & 0 & 0 & 0 & 0 & 7 & 7 & 7 & 7 & 7 & 7 \\
\hline 0.5 & 0 & 0 & 0 & 0 & 7 & 7 & 7 & 7 & 7 & 7 & 7 \\
\hline 0.6 & 0 & 0 & 0 & 6 & 7 & 7 & 7 & 7 & 7 & 7 & $7^{\mathrm{c}}$ \\
\hline 0.7 & 0 & 0 & 0 & 6 & 7 & 7 & 7 & 7 & $7^{\mathrm{c}}$ & $7^{\mathrm{c}}$ & $7^{\mathrm{c}}$ \\
\hline 0.8 & 0 & 0 & 0 & 6 & 7 & 7 & 7 & $7^{\mathrm{c}}$ & $7^{\mathrm{c}}$ & $7^{\mathrm{c}}$ & $7^{\mathrm{c}}$ \\
\hline 0.9 & 0 & 0 & 5 & 6 & 7 & 7 & $7^{\mathrm{c}}$ & $7^{c}$ & $7^{\mathrm{c}}$ & $7^{\mathrm{c}}$ & $7^{\mathrm{c}}$ \\
\hline 1.0 & 0 & 0 & 5 & 6 & 7 & $7^{\mathrm{c}}$ & $7^{\mathrm{c}}$ & $7^{\mathrm{c}}$ & $7^{\mathrm{c}}$ & $7^{\mathrm{c}}$ & $7^{\mathrm{c}}$ \\
\hline \multicolumn{12}{|l|}{ Mixture use $\mathrm{e}^{\mathrm{b}, \mathrm{e}}$} \\
\hline 0 & 0 & 0 & 0 & 0 & 0 & 3 & 3 & 3 & $3^{c}$ & $3^{c}$ & $3^{c}$ \\
\hline 0.1 & 0 & 0 & 0 & 0 & 6 & 6 & 5 & $5^{c}$ & $5^{\mathrm{c}}$ & $5^{\mathrm{c}}$ & $5^{c}$ \\
\hline 0.2 & 0 & 0 & 0 & 8 & 8 & 7 & $7^{\mathrm{c}}$ & $7^{\mathrm{c}}$ & $7^{\mathrm{c}}$ & $6^{\mathrm{c}}$ & $6^{\mathrm{c}}$ \\
\hline 0.3 & 0 & 0 & 8 & 8 & 7 & $7^{\mathrm{c}}$ & $7^{\mathrm{c}}$ & $7^{\mathrm{c}}$ & $7^{\mathrm{c}}$ & $6^{\mathrm{c}}$ & $6^{c}$ \\
\hline 0.4 & 0 & 6 & 8 & 7 & $7^{\mathrm{c}}$ & $7^{\mathrm{c}}$ & $7^{\mathrm{c}}$ & $7^{\mathrm{c}}$ & $6^{c}$ & $6^{c}$ & $6^{c}$ \\
\hline 0.5 & 3 & 6 & 7 & $7^{\mathrm{c}}$ & $7^{\mathrm{c}}$ & $7^{c}$ & $7^{\mathrm{c}}$ & $6^{c}$ & $6^{c}$ & $6^{\mathrm{c}}$ & $6^{c}$ \\
\hline 0.6 & 3 & 5 & $7^{\mathrm{c}}$ & $7^{\mathrm{c}}$ & $7^{\mathrm{c}}$ & $7^{\mathrm{c}}$ & $6^{c}$ & $6^{c}$ & $6^{c}$ & $6^{c}$ & $6^{c}$ \\
\hline 0.7 & 3 & $5^{\mathrm{c}}$ & $7^{\mathrm{c}}$ & $7^{\mathrm{c}}$ & $7^{\mathrm{c}}$ & $6^{\mathrm{c}}$ & $6^{\mathrm{c}}$ & $6^{c}$ & $6^{c}$ & $6^{\mathrm{c}}$ & $6^{\mathrm{c}}$ \\
\hline 0.8 & $3^{c}$ & $5^{\mathrm{c}}$ & $7^{\mathrm{c}}$ & $7^{\mathrm{c}}$ & $6^{\mathrm{c}}$ & $6^{\mathrm{c}}$ & $6^{\mathrm{c}}$ & $6^{\mathrm{c}}$ & $6^{\mathrm{c}}$ & $6^{c}$ & $6^{\mathrm{c}}$ \\
\hline 0.9 & $3^{c}$ & $5^{\mathrm{c}}$ & $6^{c}$ & $6^{c}$ & $6^{c}$ & $6^{c}$ & $6^{c}$ & $6^{c}$ & $6^{c}$ & $6^{c}$ & $6^{c}$ \\
\hline 1.0 & $3^{c}$ & $5^{\mathrm{c}}$ & $6^{c}$ & $6^{c}$ & $6^{c}$ & $6^{\mathrm{c}}$ & $6^{c}$ & $6^{c}$ & $6^{c}$ & $6^{c}$ & $6^{c}$ \\
\hline
\end{tabular}

a Fungicide doses are expressed as a fraction of the label recommended dose.

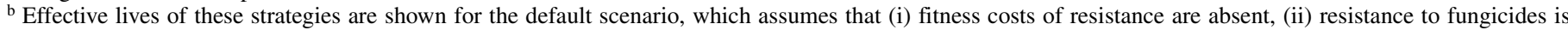
complete, and (iii) the dose-response curves and decay rates of fungicides A and B are the same. The frequency of the double-resistant strain at the start of a treatment strategy was $10^{-10}$.

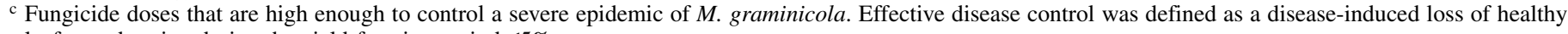
leaf area duration during the yield-forming period $\leq 5 \%$.

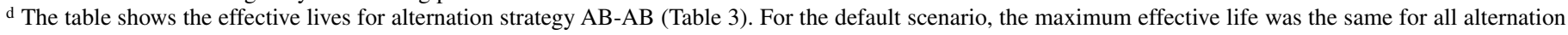
strategies.

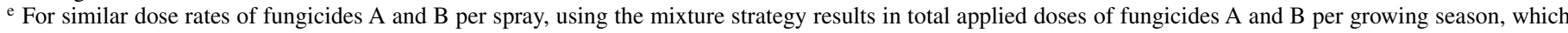
are twice as high as when using the alternation strategy (each fungicide is applied twice per growing season when using the mixture strategy but once when using the alternation strategy). For concurrent use, the total applied dose of a fungicide per growing season differs between the two sets of fields, because each fungicide is applied in only one set of fields. When the dose rates of fungicides A and B per spray are similar for the concurrent use and alternation strategies, these strategies result in the same total applied doses of fungicides A and B per growing season when averaged across both sets of fields. 
ment strategies, except for a one-year decrease in the maximum effective life of the mixture strategy and alternation strategy AB$\mathrm{AB}$ at an initial frequency of the double-resistant strain of $10^{-15}$. Increasing the efficacy of fungicide $B$ relative to fungicide A did not affect the maximum effective life of strategies for initial frequencies of the double-resistant strain of $10^{-10}$ and $10^{-5}$. For an initial frequency of $10^{-15}$, the maximum effective life of the mixture strategy and alternation strategy $\mathrm{AB}-\mathrm{AB}$ decreased with increasing efficacy of fungicide $\mathrm{B}$ by one year. Consequently, compared with the default scenario, the differences in the maximum effective lives between strategies were unaffected or only slightly changed by changing the dose-response curve and decay rate of fungicide $\mathrm{B}$ relative to fungicide $\mathrm{A}$. In all cases, the maximum effective life of the mixture strategy was either higher than the maximum effective of the other strategies or was among the strategies with the highest maximum effective life.

The effect of fitness costs of resistance. The maximum effective lives of the resistance management strategies stayed the same or increased with increasing fitness costs of resistance. The impact of fitness costs of resistance differed between the first scenario (with fitness costs for all resistant strains) and the second scenario (with fitness costs for the double-resistant strain only). For the first scenario (Fig. 5), the maximum effective lives of all strategies increased with increasing fitness costs of resistance for all initial frequencies of the double-resistant strain. For the second scenario (Fig. 5), only the maximum effective life of the mixture strategy increased with increasing fitness costs of resistance for all initial frequencies of the double-resistant strain. For this scenario, the maximum effective lives of the alternation strategies only substantially increased with increasing fitness costs of resistance, when the initial frequency of the double-resistant strain was $10^{-5}$. The maximum effective life of the concurrent use strategy was unaffected or only slightly affected ( $\leq 1$ year) by fitness costs of resistance for the second scenario. Hence, for all combinations of fitness costs of resistance and initial frequencies of the doubleresistant strain, the maximum effective life of the mixture strategy was equal to or higher than the maximum effective life of the other strategies. The difference in the maximum effective life between the mixture strategy and the other resistance management strategies was not affected or was increased with increasing fitness costs of resistance.

The effect of partial resistance to fungicides. Partial resistance was represented in the model by either changing the asymptote or the curvature parameter of the dose-response curve of the sensitive strain (Fig. 2). For each method, we determined the maximum effective life of resistance management strategies for a scenario with complete resistance to fungicide A and partial resistance to fungicide $\mathrm{B}$ and for a scenario with partial resistance to both fungicides.

When modeling partial resistance by changing the asymptote or the curvature of the dose-response curve, in general, the maximum effective life of the resistance management strategies increased with decreasing level of resistance to fungicides for all initial frequencies of the double-resistant strain (Figs. 6 and 7). The maximum effective life of the mixture strategy was most sensitive and the maximum effective life of the concurrent use strategy was least sensitive to changes in the level of partial resistance for all initial frequencies of the double-resistant strain and for both scenarios. When resistance to fungicide $\mathrm{A}$ was complete and resistance to fungicide $\mathrm{B}$ was partial, the maximum effective life of the concurrent use strategy was not affected by changes in the level of resistance for initial frequencies of the double-resistant strain of $10^{-15}$ and $10^{-10}$. For all initial frequencies of the double-resistant strain, the increase in the maximum effective life of resistance management strategies was higher when resistance to both fungicides $\mathrm{A}$ and $\mathrm{B}$ was decreased instead of resistance to fungicide B only.

Thus, for all combinations of partial resistance and the initial frequency of the double-resistant strain, the maximum effective life of the mixture strategy was equal to or higher than the maximum effective life of the other strategies. The difference in the maximum effective life between the mixture strategy and the other resistance management strategies increased or was not affected by decreasing the degree of resistance.

The effect of dose. For most scenarios and initial frequencies of the double-resistant strain, the effective life of resistance management strategies was maximized by applying fungicide doses that were just sufficient to provide effective control of a severe epidemic (Table 5). Exceptions occurred for the mixture strategy when the resistance of pathogen strains to fungicides was partial instead of complete, especially when partial resistance was modeled by adjusting the curvature parameter of a dose-response curve of the sensitive strain. In this case, the lowest doses that maximized the effective life of the resistance management strategies could be substantially higher than lowest doses necessary for disease control.

For the concurrent use and alternation strategies, the differences between the minimum fungicide doses necessary for effective disease control and the label-recommended fungicide doses were small and the maximum effective life could, in a large number of cases, also be obtained by applying fungicides at the label dose. However, for the mixture strategy, the differences between the minimum fungicide doses necessary for effective disease control and the label-recommended fungicide doses were higher. This is because the maximum sum of the total applied doses of fungicides A and B per growing season was twice as high for the mixture strategy as for the concurrent use (when averaged over the two sets of fields) and alternation strategies (Table 3). For the mixture strategy, the maximum effective life usually could not be obtained by applying fungicides $\mathrm{A}$ and $\mathrm{B}$ at the label dose rate for initial frequencies of the double-resistant strain of $10^{-10}$ and $10^{-15}$. Exceptions occurred for the scenario with partial resistance to both fungicides, especially when partial resistance was modeled by adjusting the dose-response curvature parameter. However, for initial frequencies of the double-resistant strain of $10^{-5}$, the maximum effective life of the mixture strategy could often be reached by applying fungicides at the label dose rate, except for scenarios that accounted for fitness costs of resistance and for scenarios with complete resistance to one and partial resistance to the other fungicide.

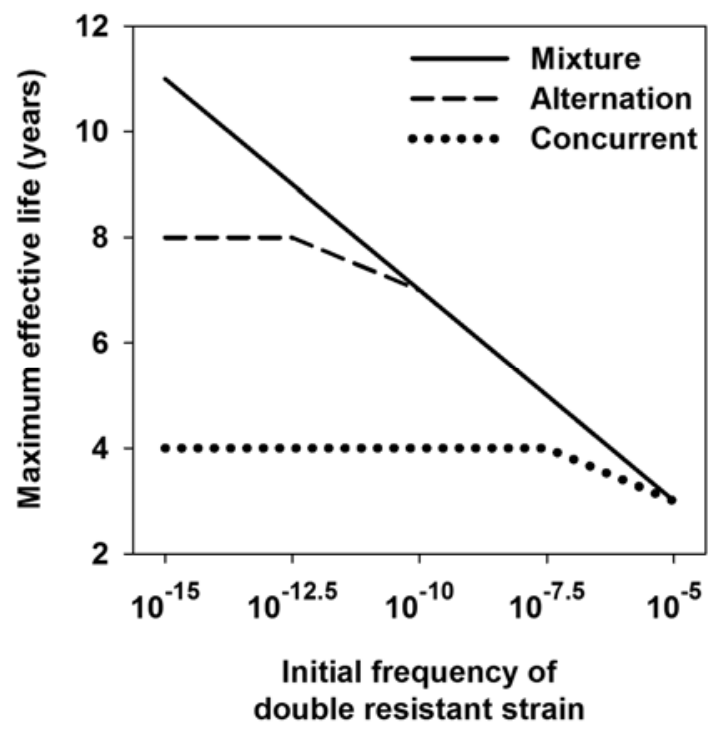

Fig. 4. Maximum effective life for concurrent, alternating, and mixture use of two high-risk fungicides as a function of the frequency of the double-resistant strain at the start of the first growing season. Frequencies of both single-resistant strains at the start of the first growing season were $10^{-5}$. The maximum effective lives of the three alternation strategies (Table 3) were the same. 
The combinations of the doses of fungicides A and B, which maximized the effective life achievable by a particular resistance management strategy, exerted an approximately equal selection pressure on both single-resistant strains (Table 6; Supplemental Tables 1 and 2), except in the scenario where strains were completely resistant to fungicide A and partially resistant to fungicide $\mathrm{B}$.

\section{DISCUSSION}

We compared the effective lives of two high-risk fungicides with different MOA applied as a mixture, alternately, or concurrently for (i) different levels of fitness costs of resistance, (ii) different levels of insensitivity, (iii) different combinations of high-risk fungicides, and (iv) different initial frequencies of the double-resistant strain. The results suggest that the mixture strategy is better than or equal to alternation strategies, which are better than or equal to concurrent use. The benefit to effective life from the mixture strategy increased with increasing fitness costs of resistance, decreasing levels of resistance, and a decreasing initial frequency of the double-resistant strain but was not affected by differences in the dose-response curves and decay rates between the two-high risk fungicides in the mixture.

The effective life from the mixture strategy may be higher than from the concurrent and alternate use strategy for the following reasons. First, in contrast to the alternation and concurrent use strategies, disease control by the mixture strategy is not affected by selection for the single-resistant strains, because a pathogen strain that carries resistance to only one MOA in the mixture would be controlled by the other fungicide in the mixture. Therefore, the effective life achieved from the mixture strategy is determined by the time that it takes the double-resistant strain to

Fitness costs for all resistant strains

\section{Fitness costs for rArB}
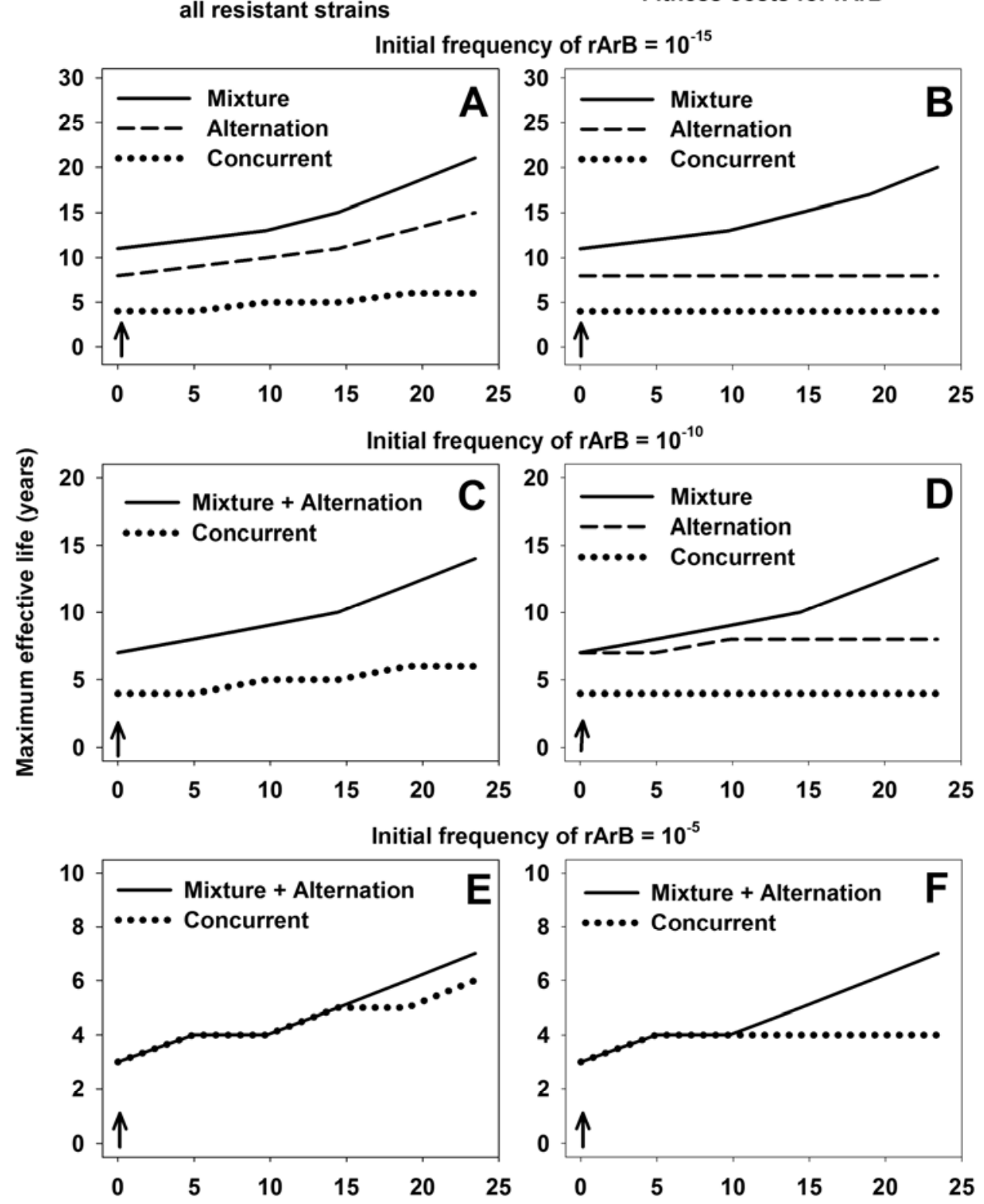

Fitness costs of resistance (\% reduction of infection efficiency)

Fig. 5. Maximum effective lives for concurrent, alternating, and mixture use of two fungicides as a function of the fitness costs of resistance for the doubleresistant strain, when the frequency of the double-resistant strain at the start of the first growing season amounts to $\mathbf{A}$ and $\mathbf{B}, 10^{-15} ; \mathbf{C}$ and $\mathbf{D}, 10^{-10} ;$ and $\mathbf{E}$ and $\mathbf{F}$, $10^{-5}$ for scenarios with fitness costs for all resistant strains (A, C, and $\left.\mathbf{E}\right)$ and with fitness costs for the double-resistant strain only $(\mathbf{B}, \mathbf{D}$, and $\mathbf{F})$. Frequencies of both single-resistant strains at the start of the first growing season were $10^{-5}$. The maximum effective lives of the three alternation strategies (Table 3 ) were the same. Arrows indicate the maximum effective life of resistance management strategies for the default scenario (see text). 
reach frequencies high enough to affect disease control. Second, for fungicide doses that resulted in the highest effective life, the selection pressure on the double-resistant strain was approximately similar for the different resistance management strategies but sometimes lower for the mixture strategy. Therefore, the effective life from the mixture strategy is higher than from the concurrent and alternate use strategies when the single-resistant strains affect disease control by the concurrent and alternate use strategy more quickly than the double-resistant strain. This is the case when the initial frequency of the double-resistant strain is sufficiently low relative to the initial frequency of the singleresistant strains, because the selection pressure on the doubleresistant strain is higher than on the single-resistant strains.

The results suggest that, for most scenarios, effective life can be maximized by applying fungicide doses that are just high enough to provide effective control. This is because the difference in fitness between a sensitive and a resistant strain (and, therefore, the selection for the resistant strain) increases when the dose of a fungicide increases. However, when partial resistance was modeled by adjusting the curvature of dose-response curves, the lowest fungicide doses that resulted in the maximum effective life were, in some cases, much higher than the fungicide doses necessary for sufficient disease control, especially for the mixture strategy. This may be explained by convergence of the dose-response curves of the sensitive and partially resistant strains at high fungicide doses. As a result of this convergence, the difference in fitness between the sensitive and resistant strain (and, therefore, the selection for the resistant strain) becomes smaller for higher fungicide doses. However, to the best of our knowledge, published data from experiments on the selection for resistance as a function of the

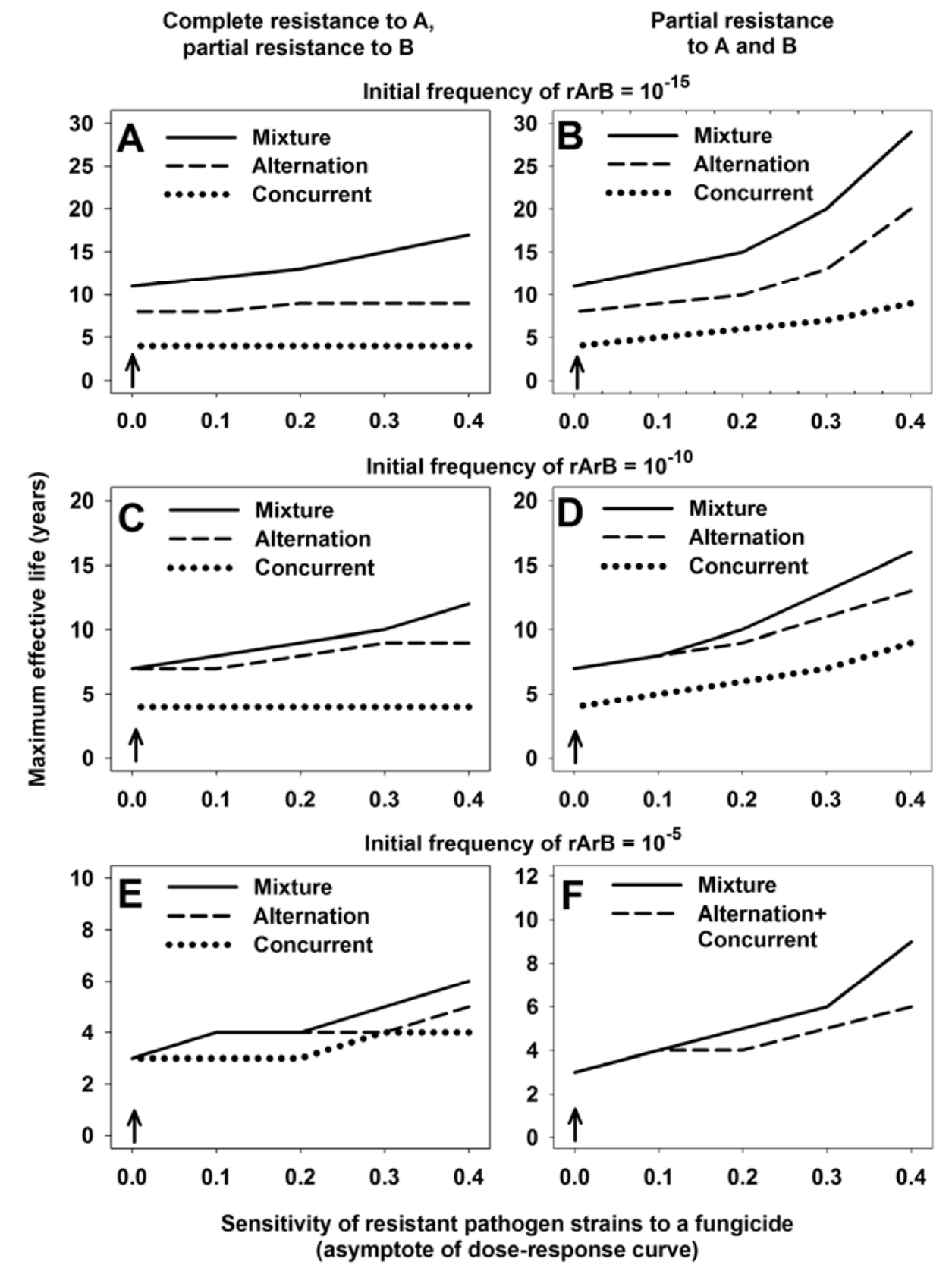

Fig. 6. Maximum effective lives for concurrent, alternating, and mixture use of two fungicides A and B as a function of the sensitivity of partially resistant pathogen strains to fungicides, when partial resistance is modeled by adjusting the asymptote of dose-response curves. Frequencies of the double-resistant strain were $\mathbf{A}$ and $\mathbf{B}, 10^{-15} ; \mathbf{C}$ and $\mathbf{D}, 10^{-10}$; and $\mathbf{E}$ and $\mathbf{F}, 10^{-5}$ for a scenario with complete resistance to fungicide A and partial resistance to fungicide B (A, C, and $\left.\mathbf{E}\right)$ and for a scenario with partial resistance to both fungicides $(\mathbf{B}, \mathbf{D}$, and $\mathbf{F})$. Frequencies of both single-resistant strains at the start of the first growing season were $10^{-5}$. The maximum effective lives of the three alternation strategies (Table 3) were the same. Arrows indicate the maximum effective life of resistance management strategies for the default scenario (see text). 
dose rate of fungicides show that the selection for resistance increases with the dose rate of fungicides (28), suggesting that convergence of dose-response curves may be of limited practical relevance.

It is not practical to determine the maximum effective life of a resistance management strategy experimentally due to the required length of the experiments and due to the large number of combinations of the dose rates of the two high-risk fungicides for which the emergence time should be determined. However, the effects on selection reported from experiments can be compared against the effects reported here from modeling. Some evidence has been reported in the literature from experiments that followed the selection for resistance against two fungicides as a result of exposure to a mixture. One of the studies reported that mixture use selected for resistance to both fungicides in the mixture (22). This is in agreement with our model predictions, which show that mixture use increases the frequency of all resistant strains in the pathogen population, because they have a higher fitness than the sensitive strain in the presence of fungicides. Brent et al. (4) reported that exposure to a mixture of fungicides did not significantly change the sensitivity of the pathogen population to these fungicides, whereas single use of fungicides did. Zhang et al. (45) did not study the selection for resistance by solo use of fungicides but also reported that, in the short term, exposure to a mixture of fungicides did not significantly change the sensitivity of the pathogen population to these fungicides. Both studies reported evidence for negative cross-resistance (a decrease in the sensitivity of the pathogen population to one fungicide was accompanied by an increase in the sensitivity to the other fungicide in the mixture), which may explain the absence of a significant shift in the sensitivity of the pathogen population in response to the mixture use of fungicides. In our model simulations, we did not account for negative cross-resistance.

Many experimental studies have compared the selection for resistance to a high-risk fungicide applied alone or applied in a mixture with a high-risk fungicide with a different MOA in a range of host-pathogen systems. Hereafter, we will denote the high-risk fungicide for which the development of resistance was determined as the "to-be-protected fungicide". The experiments described in these articles can be divided into two groups. In the first type of experiment, the dose rate of the to-be-protected fungicide is the same when applied alone and applied in a mixture $(3,4,9,11,14,18,26,28,30,40)$. In the second type of experiment, the dose rate of the to-be-protected fungicide was lower in the mixture then when applied alone $(7,8,10,11,17,30,38)$. The first type of experiment was conducted for 14 pathogen-crop-fungicide mixture combinations. In 11 of these 14 cases, mixing reduced the selection for resistance to the to-be-protected fungicide $(3,4,11,14,18,28,30)$. For one pathogen-crop-fungicide mixture combination, mixing did delay the selection for resistance com-

TABLE 5. Ranges of fungicide doses for which the effective lives of concurrent (Con), alternating (Alt), and mixture (Mix) use of two high-risk fungicides were highest for frequencies of the double-resistant strain $\left(\theta_{A B}\right)$ at the start of a treatment strategy amounting to $10^{-15}, 10^{-10}$, or $10^{-5}$ for different scenarios for the efficacy of fungicides, fitness costs of resistance, and sensitivity of resistant strains ${ }^{\mathrm{a}}$

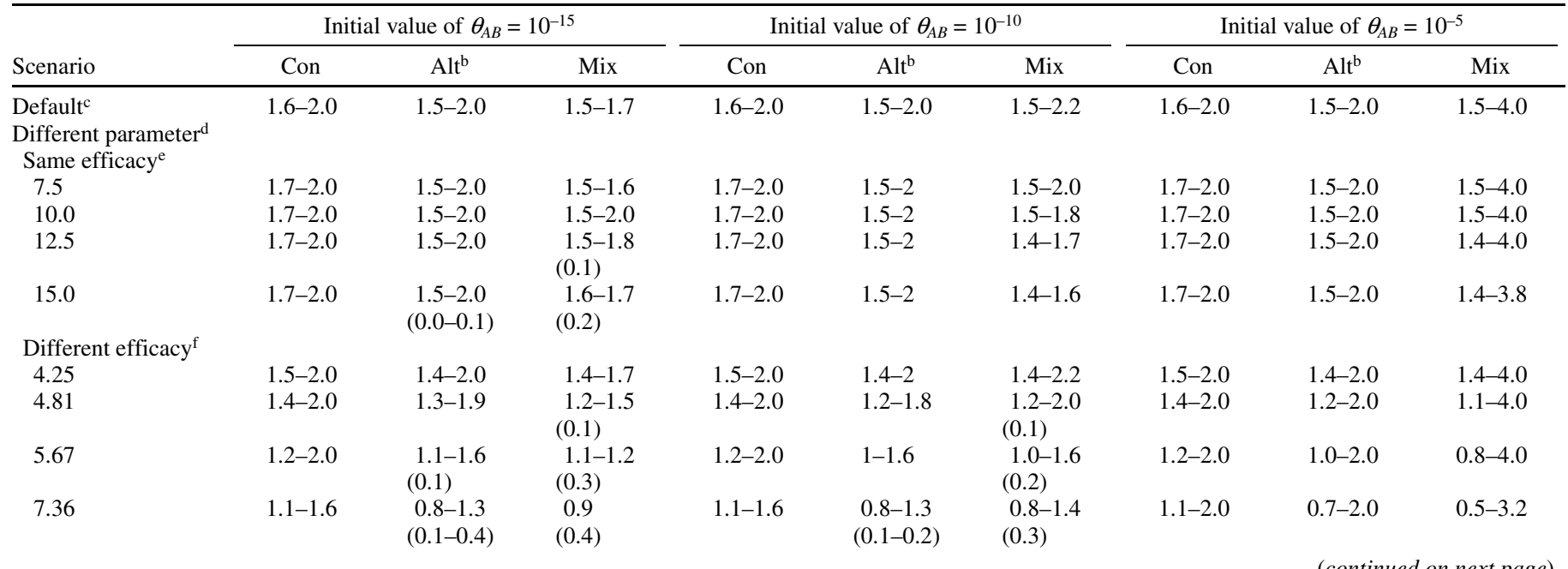

${ }^{a}$ Fungicide dose represents the sum of the doses of two high-risk fungicides, applied per growing season, when the doses of both fungicides are expressed as a fraction of the label recommended dose. For concurrent use, the fungicide dose was divided by two to account for the fact that each fungicide is applied in only one of the two sets of fields. Values in parentheses indicate the difference between the lowest fungicide dose, which results in the maximum effective life of a resistance management strategy, and the lowest dose for which this strategy provides sufficient control of a severe epidemic. This difference is not shown when both fungicide doses are the same. The maximum fungicide dose applied per growing season is two times the label dose for concurrent and alternating use (two sprays per growing season, one fungicide applied per spray time) and four times the label dose for mixtures (two sprays per growing season, two fungicides applied per spray time).

${ }^{\mathrm{b}}$ Combined ranges of fungicide doses for which the effective lives of the three evaluated alternation strategies were highest (Table 3).

c This is the most simple scenario, which assumes that there are no fitness costs of resistance, that resistance to fungicides is complete, and that the two high-risk fungicides have independent modes of actions but are otherwise identical, with a half-life of 4.1 days and curvature parameter of 9.6. Footnotes below explain how the other scenarios in the table differ from the default scenario.

${ }^{\mathrm{d}}$ Fungicides have different parameter values, with the same or different efficacy.

e The first column gives the value of the half-life time of fungicide B in days. The corresponding values of the curvature parameter $\left(\beta_{B}\right)$ are $2.8,1.88,1.46$, and 1.22 , respectively.

f The first column gives the value of the half-life time of fungicide B in days.

g Fitness costs of resistance for the single-resistant (SR) and double-resistant (DR) strains and for the DR strain only.

${ }^{\mathrm{h}}$ The first column gives the percent reduction of the infection efficiency of the DR strain due to fitness costs of resistance. The corresponding reduction of the infection efficiency of the SR strains due to fitness costs of resistance were $2.5,5,7.5,10$, and $12.5 \%$.

${ }^{i}$ The first column gives the percent reduction of the infection efficiency of the DR strain due to fitness costs of resistance.

j Complete resistance to fungicide A, partial resistance to fungicide B. Asymptote method: the first column gives the maximum reduction of the life-cycle parameters of partially resistant strains by fungicides. Curvature method: the first column gives the curvature parameter of the dose-response curves of the partially resistant strains.

${ }^{k}$ Partial resistance to both fungicides A and B. 
pared with single use in one experiment but not in another (26). In only two cases did mixing not affect the selection for resistance compared with single use $(9,40)$. Our modeling study suggests that the selection for resistance to one of the high-risk fungicides in the mixture decreases when this fungicide is applied at a constant dose rate and the dose rate of the other high-risk fungicide in the mixture is increased. This is in agreement with most of the experimental evidence $(3,4,11,14,18,28,30)$.

The second type of experiment was conducted for nine pathogen-crop-fungicide mixture combinations. In six cases, mixing reduced the selection for resistance to the to-be-protected fungicide $(8,11,17,30)$. For one pathogen-crop-fungicide mixture combination, mixing did delay the selection for resistance compared with single use in one experiment but not in another (7). In two cases, mixing did not affect the selection for resistance compared with solo use $(10,38)$. Our modeling study suggests that reducing the dose rate of one mixture component and increasing the dose rate of the other mixture component reduces the selection pressure on the first mixture component. Therefore, the model output is in agreement with the experimental evidence above for the majority of pathogen-crop-fungicide mixture combinations.
To the best of our knowledge, there are only two experimental articles which compare the development of resistance to a highrisk (to-be-protected) fungicide in a mixture or alternated with a high-risk fungicide with a different MOA for similar total applied fungicide doses. In one study, the development of resistance to the to-be-protected fungicide was lowest for the mixture strategy (30). In the other study, mixtures decreased the development of resistance more than alternation for one combination of host, pathogen, and fungicides but the opposite was the case for another combination (17). Our model predicted that a mixture of high-risk fungicides $\mathrm{A}$ and $\mathrm{B}$ selected less for resistance to fungicide A than alternation, except for a combination of a highdose rate of fungicide $A$ and a low-dose rate of fungicide $B$ or the scenario with fungicide B having efficiency similar to but doseresponse curve different from fungicide A. However, the number of experimental articles is too small to allow a meaningful comparison of the model predictions with the literature data. To our knowledge, there is no experimental literature on the selection for resistance by concurrent use of two fungicides.

In our modeling study, we assumed that resistance was present to both high-risk fungicides in a mixture. In most experiments

TABLE 5. (continued from preceding page)

\begin{tabular}{|c|c|c|c|c|c|c|c|c|c|}
\hline \multirow[b]{2}{*}{ Scenario } & \multicolumn{3}{|c|}{ Initial value of $\theta_{A B}=10^{-15}$} & \multicolumn{3}{|c|}{ Initial value of $\theta_{A B}=10^{-10}$} & \multicolumn{3}{|c|}{ Initial value of $\theta_{A B}=10^{-5}$} \\
\hline & Con & $A l t^{\mathrm{b}}$ & Mix & Con & $A l t^{b}$ & Mix & Con & Alt ${ }^{\mathrm{b}}$ & Mix \\
\hline \multicolumn{10}{|c|}{ Fitness costs ${ }^{g}$} \\
\hline \multicolumn{10}{|c|}{ SR and DR strains ${ }^{h}$} \\
\hline 4.9 & $1.6-2.0$ & $\begin{array}{c}1.5-2.0 \\
(0.0-0.1)\end{array}$ & $1.5-1.8$ & $1.6-2.0$ & $1.5-1.7$ & $1.5-1.8$ & $1.6-1.8$ & $1.5-2.0$ & $1.5-2.0$ \\
\hline 9.8 & $1.6-1.8$ & $1.5-2.0$ & 1.5 & $1.6-1.8$ & $1.5-1.6$ & $1.5-1.7$ & $1.6-2.0$ & $1.5-2.0$ & $1.5-3.6$ \\
\hline 14 & $1.6-2.0$ & $1.5-2.0$ & 1.5 & $1.6-2.0$ & $1.5-1.7$ & $1.5-1.8$ & $1.6-1.6$ & $1.5-1.9$ & $1.5-1.9$ \\
\hline 19 & $1.6-1.6$ & $1.5-2.0$ & $1.5-1.6$ & 1.6 & 1.5 & $1.5-1.6$ & $1.6-2.0$ & $1.5-1.7$ & $1.5-1.6$ \\
\hline 23 & $1.6-1.6$ & $1.5-2.0$ & $1.5-1.6$ & 1.6 & 1.5 & $1.5-1.6$ & $1.6-2.0$ & $1.5-1.7$ & $1.5-1.6$ \\
\hline \multicolumn{10}{|c|}{ DR strain only ${ }^{\mathrm{i}}$} \\
\hline 4.9 & $1.6-2.0$ & $1.5-2.0$ & $1.5-1.8$ & $1.6-2.0$ & $1.5-2.0$ & $1.5-1.8$ & 1.6 & $1.5-2.0$ & $1.5-2.0$ \\
\hline 9.8 & $1.6-2.0$ & $1.5-2.0$ & 1.5 & $1.6-2.0$ & $1.5-2.0$ & $1.5-1.7$ & $1.6-2.0$ & $1.5-2.0$ & $1.5-3.6$ \\
\hline 14 & $1.6-2.0$ & $1.5-2.0$ & $1.5-1.8$ & $1.6-2.0$ & $1.5-2.0$ & $1.5-1.8$ & $1.6-2.0$ & $1.5-1.9$ & $1.5-1.9$ \\
\hline 19 & $1.6-2.0$ & $1.5-2.0$ & $\begin{array}{l}1.6-1.8 \\
(0.1)\end{array}$ & $1.6-2.0$ & $1.5-2.0$ & $1.5-1.6$ & $1.6-2.0$ & $1.5-1.6$ & $1.5-1.6$ \\
\hline 23 & $1.6-2.0$ & $1.5-2.0$ & $\begin{array}{l}1.6-1.8 \\
(0.1)\end{array}$ & $1.6-2.0$ & $1.5-2.0$ & $1.5-1.6$ & $1.6-2.0$ & $1.5-1.6$ & $1.5-1.6$ \\
\hline \multicolumn{10}{|c|}{ Partial resistance } \\
\hline \multicolumn{10}{|c|}{ Comp. A, part. $\mathrm{B}^{\mathrm{j}}$} \\
\hline 0.1 & $1.6-2.0$ & $1.5-2.0$ & $1.5-1.7$ & $1.6-2.0$ & $1.5-2.0$ & $1.5-1.8$ & $1.6-2.0$ & $1.5-1.7$ & $1.5-2.2$ \\
\hline 0.2 & $1.6-2.0$ & $\begin{array}{c}1.5-1.9 \\
(0.0-0.1)\end{array}$ & $1.5-2.0$ & $1.6-2.0$ & $1.5-2.0$ & $1.5-1.6$ & $1.6-2.0$ & $1.5-2.0$ & $1.5-4.0$ \\
\hline 0.3 & $1.6-2.0$ & $\begin{array}{c}1.5-1.8 \\
(0.0-0.1)\end{array}$ & $1.5-1.8$ & $1.6-2.0$ & $\begin{array}{l}1.5-1.7 \\
(0-0.1)\end{array}$ & $1.5-2.0$ & $1.6-1.7$ & $1.5-2.0$ & $1.5-2.6$ \\
\hline 0.4 & $1.6-2.0$ & $\begin{array}{c}1.5-1.8 \\
(0.0-0.1)\end{array}$ & $1.5-2.6$ & $1.6-2.0$ & $\begin{array}{l}1.5-1.9 \\
(0-0.1)\end{array}$ & $\begin{array}{c}1.6 \\
(0.1)\end{array}$ & $1.6-1.8$ & $\begin{array}{c}1.5-1.7 \\
(0.0-0.1)\end{array}$ & $\begin{array}{l}1.6-2.4 \\
(0.1)\end{array}$ \\
\hline \multicolumn{10}{|c|}{ Curvature method } \\
\hline 1 & $1.6-2.0$ & $\begin{array}{l}1.5-2 \\
(0.0-0.1)\end{array}$ & $\begin{array}{l}2.6-2.8 \\
(1.1)\end{array}$ & $1.6-2.0$ & $\begin{array}{l}1.5-1.7 \\
(0-0.1)\end{array}$ & $1.5-3.4$ & 1.6 & $1.5-2.0$ & $\begin{array}{l}1.6-2.6 \\
(0.1)\end{array}$ \\
\hline 2 & $1.6-2.0$ & $\begin{array}{l}1.5-2 \\
(0.0-0.1)\end{array}$ & $\begin{array}{c}2.4 \\
(0.9)\end{array}$ & $1.6-2.0$ & $\begin{array}{l}1.5-1.8 \\
(0-0.1)\end{array}$ & $\begin{array}{l}2.2-2.6 \\
(0.7)\end{array}$ & $1.6-1.9$ & $1.5-2.0$ & $\begin{array}{l}1.8-2.6 \\
(0.3)\end{array}$ \\
\hline 3 & $1.6-2.0$ & $\begin{array}{l}1.5-2 \\
(0.0-0.1)\end{array}$ & $\begin{array}{c}2.2 \\
(0.7)\end{array}$ & $1.6-2.0$ & $\begin{array}{c}1.5-1.8 \\
(0.0-0.1)\end{array}$ & $\begin{array}{c}2.2 \\
(0.7)\end{array}$ & $1.6-2.0$ & $\begin{array}{c}1.5-1.7 \\
(0.0-0.1)\end{array}$ & $\begin{array}{l}1.8-2.4 \\
(0.3)\end{array}$ \\
\hline \multicolumn{10}{|c|}{ Both $\mathrm{A}$ and $\mathrm{B}^{\mathrm{k}}$} \\
\hline \multicolumn{10}{|c|}{ Asymptote method } \\
\hline 0.1 & $1.6-2.0$ & $1.5-2.0$ & $1.5-1.7$ & $1.6-2.0$ & $1.5-2.0$ & $1.5-2.8$ & $1.6-2.0$ & $1.5-2.0$ & $1.5-4.0$ \\
\hline 0.2 & $1.6-1.7$ & $1.5-2.0$ & 1.5 & $1.6-1.7$ & $1.5-2.0$ & $1.5-2.4$ & $1.6-2.0$ & $1.5-2.0$ & $1.5-4.0$ \\
\hline 0.3 & $1.6-2.0$ & $\begin{array}{c}2.0 \\
(0.5)\end{array}$ & $\begin{array}{l}2.4-2.6 \\
(0.9)\end{array}$ & $1.6-2.0$ & $1.5-1.7$ & $1.5-1.6$ & $1.6-2.0$ & $1.5-2.0$ & $1.5-4.0$ \\
\hline 0.4 & 1.6 & $\begin{array}{c}2.0 \\
(0.5)\end{array}$ & $\begin{array}{c}2.6 \\
(1.1)\end{array}$ & $1.6-1.6$ & $1.5-1.8$ & $1.5-4.0$ & $1.6-2.0$ & $1.5-2.0$ & $\begin{array}{l}3.6-4.0 \\
(2.1)\end{array}$ \\
\hline \multicolumn{10}{|c|}{ Curvature method } \\
\hline 0.5 & $1.6-2.0$ & $\begin{array}{l}1.8-2.0 \\
(0.3)\end{array}$ & $1.5-2.0$ & $1.6-2.0$ & $1.5-2.0$ & $1.5-4.0$ & $1.6-2.0$ & $1.5-2.0$ & $1.5-4.0$ \\
\hline 1 & $\begin{array}{l}1.8-2.0 \\
(0.2)\end{array}$ & $\begin{array}{c}1.7-2.0 \\
(0.0-0.2)\end{array}$ & $\begin{array}{c}2.8 \\
(1.3)\end{array}$ & $\begin{array}{l}1.8-2.0 \\
(0.2)\end{array}$ & $1.5-2.0$ & $\begin{array}{l}3.2-4.0 \\
(1.7)\end{array}$ & $1.6-2.0$ & $1.5-2.0$ & $\begin{array}{l}3.6-4.0 \\
(2.1)\end{array}$ \\
\hline 1.5 & $\begin{array}{c}2.0 \\
(0.4)\end{array}$ & $\begin{array}{c}2.0 \\
(0.5)\end{array}$ & $\begin{array}{c}2.6 \\
(1.1)\end{array}$ & $\begin{array}{c}2.0 \\
(0.4)\end{array}$ & $1.5-2.0$ & $\begin{array}{l}3.4-4.0 \\
(1.9)\end{array}$ & $1.6-2.0$ & $1.5-2.0$ & $\begin{array}{l}3.8-4.0 \\
(2.3)\end{array}$ \\
\hline
\end{tabular}


above, the presence and development of resistance was only determined for one of the mixed or alternated fungicides. This raises the question of how comparable the results from our modeling study and from the experimental literature above are. It is unlikely that the selection for resistance to the to-be-protected fungicide is affected by the presence of other resistant strains through competition for healthy leaf area, unless they occur in sufficiently high frequencies in the pathogen population. If that is the case, competition for healthy leaf area between resistant strains is likely to reduce the selection for resistance to the to-be-protected fungicide. Therefore, the qualitative conclusion from most experiments that mixing reduces the selection for resistance to the to-beprotected fungicide compared with single use probably is not affected by the presence or absence of resistance to the mixture partner.

For a more rigorous test of the predictive power of the model, experiments could be conducted to test the mechanisms which explain the success of the mixture strategy. Our model suggests that the mixture strategy has an equal or higher effective life than concurrent and alternating use, because (i) it is able to control both single-resistant strains and (ii) concurrent use and alternation exert approximately the same selection pressure on the doubleresistant strain as the mixture strategy for similar total applied doses. The first point can be tested by conducting experiments in which the effect of selection for both single- and double-resistant strains on disease control is measured in response to concurrent,

\section{Complete resistance to $A$, partial resisance to $B$}

\section{Partial resistance to $A$ and $B$}
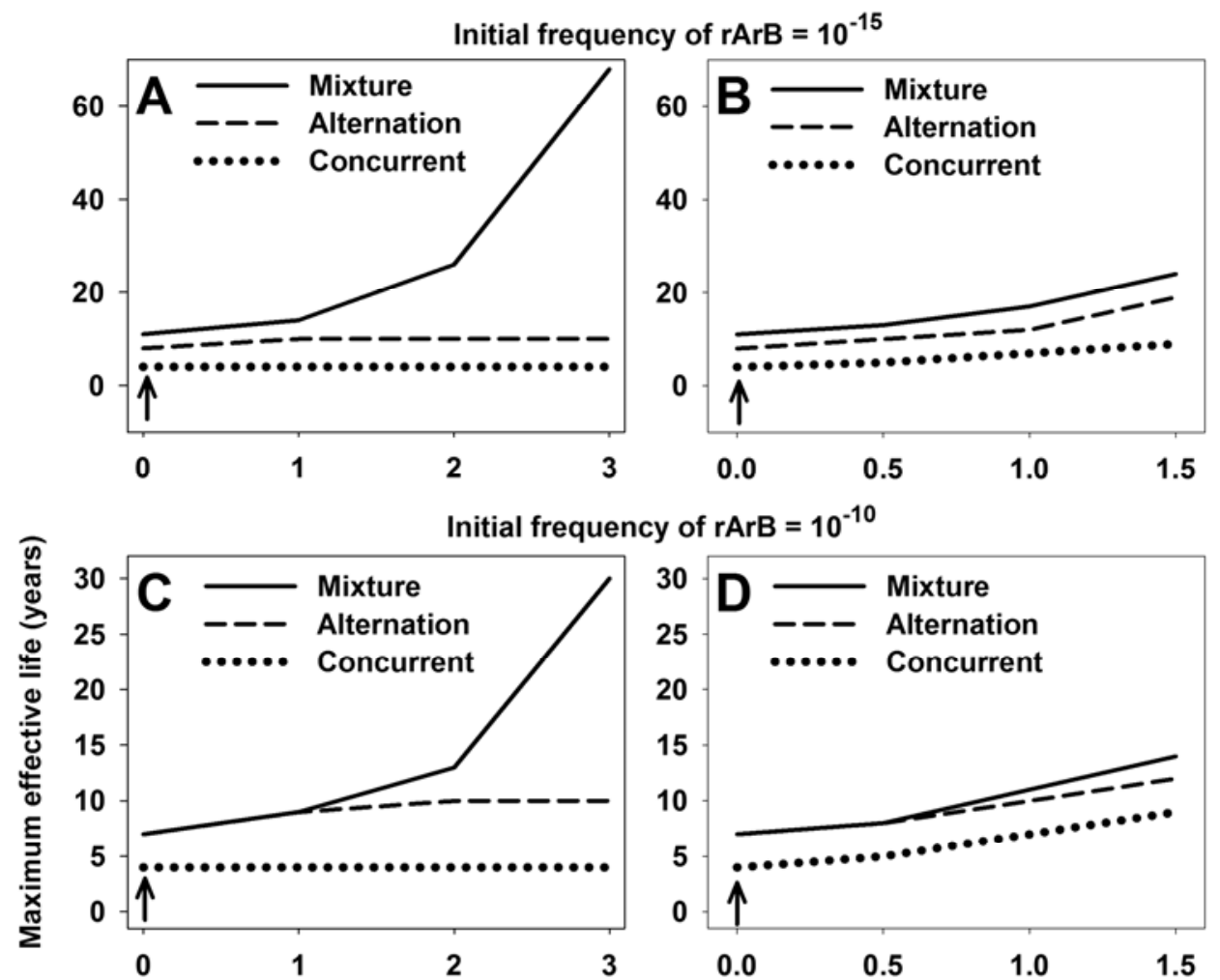

Initial frequency of $\mathrm{rArB}=10^{-5}$
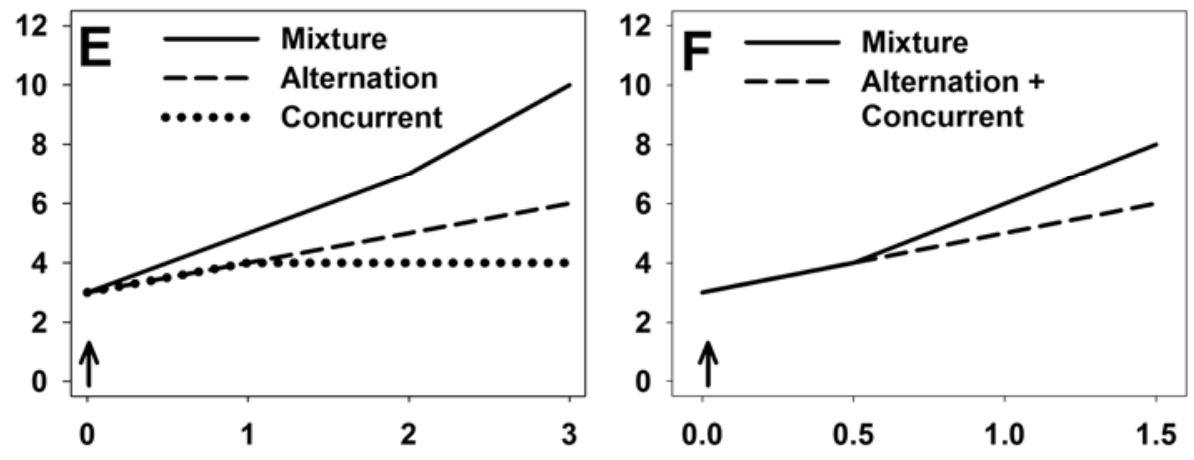

Sensitvity of resistant pathogen strains to a fungicide (curvature of dose-response curve)

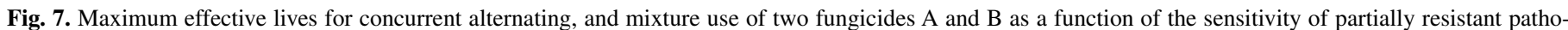

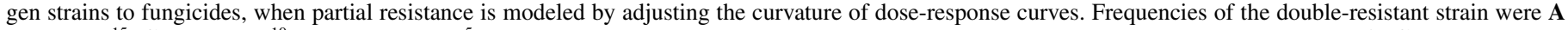

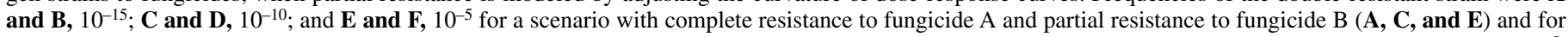

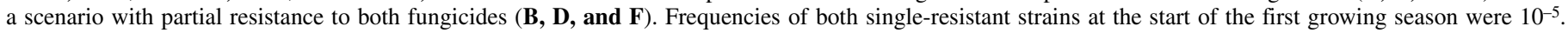

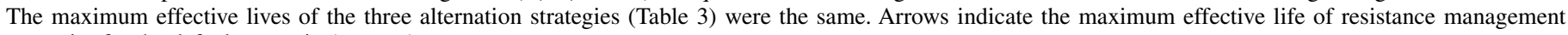
strategies for the default scenario (see text). 
alternating, and mixture use of two high-risk fungicides. In order to test the second point, the total applied fungicide doses in these experiments should be the same for all treatment strategies. Ideally, the frequency of the different resistant strains in the inoculum which is used to infect the hosts at the start of an experiment is the same for the different treatment strategies. In field experiments, the influx of spores from surrounding areas will make it more difficult to detect differences in the selection for resistance and disease control between treatment strategies. This would be less of a problem in glasshouse or laboratory experiments.

A number of modeling studies have been published which compare the selection for resistance by mixtures of two fungicides against the selection for resistance by sequential or separate use

TABLE 6. Selection ratios (see text) of resistant strains during the first growing season for fungicide doses which maximize the effective life of concurrent (Con), alternating (Alt), and mixture (Mix) use of two high-risk fungicides for different scenarios given that the initial frequencies of the single and double-resistant strains amount to $10^{-5}$ and $10^{-10}$, respectively ${ }^{\mathrm{a}}$

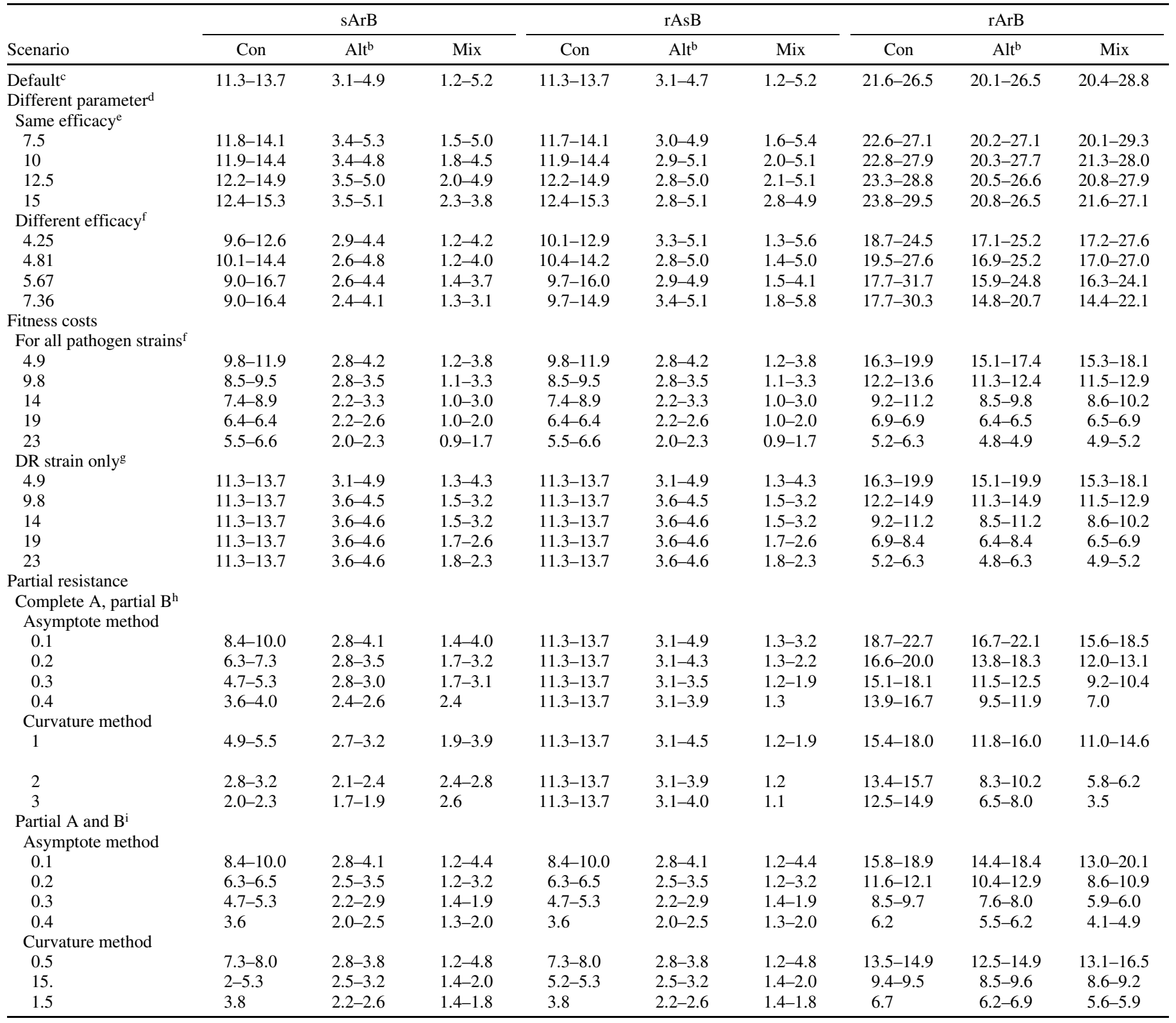

a sArB: the strain sensitive to A and resistant to B; rAsB: the strain resistant to A and sensitive to B; rArB: the strain resistant to both fungicides A and B.

${ }^{\mathrm{b}}$ Selection ratios of the three alternation strategies (Table 3 ) were pooled.

${ }^{c}$ This is the most simple scenario, which assumes that there are no fitness costs of resistance, that resistance to fungicides is complete, and that the two high-risk fungicides have independent modes of actions but are otherwise identical, with a half-life of 4.1 days and curvature parameter of 9.6. Footnotes below explain how the other scenarios in the table differ from the default scenario.

${ }^{\mathrm{d}}$ Fungicides have different parameter values, with the same or different efficacy.

e The first column gives the value of the half-life time of fungicide B in days. The corresponding values of the curvature parameter $\left(\beta_{B}\right)$ are $2.8,1.88,1.46$, and 1.22 , respectively.

${ }^{f}$ The first column gives the value of the half-life time of fungicide B in days.

$\mathrm{g}$ The first column gives the percent reduction of the infection efficiency of the double-resistant (DR) strain due to fitness costs of resistance. The corresponding reduction of the infection efficiencies of the single-resistant strains due to fitness costs of resistance were $2.5,5,7.5,10$, and $12.5 \%$.

${ }^{\text {h }}$ Complete resistance to fungicide A, partial resistance to fungicide B. Asymptote method: the first column gives the maximum reduction of the life-cycle parameters of partially resistant strains by fungicides. Curvature method: the first column gives the curvature parameter of the dose-response curves of the partially resistant strains.

i Partial resistance to both fungicides A and B. 
of two fungicides. However, in most studies, one of the fungicides was a low-risk fungicide and the other one was a high-risk fungicide $(16,19,20,21,24,27,32,37)$. Two modeling studies compared the selection for resistance by mixing two high-risk fungicides with the selection for resistance by sequential or concurrent use of two high-risk fungicides. Shaw (33) used mathematical modeling to compare the selection for resistance by sequential and mixture use of two high-risk fungicides. He concluded that mixture use will select equally or more strongly for the double-resistant strain compared against sequential use, and that any advantage of mixtures must depend on other mechanisms such as extreme rarity of the double-resistant strain. Birch and Shaw (2) derived algebraically that a fungicide is suitable for use in mixtures when it initially has the same impact on the sensitive and resistant pathogen strains until a certain dose rate is exceeded. In that case, mixtures of two high-risk fungicides may decrease the selection for resistance in comparison with concurrent use while obtaining the same level of disease control. Our study suggests that both these mechanisms may occur. The difference between the maximum effective life from the mixture strategy compared with the other resistance management strategies increased as the initial frequency of the double-resistant strain decreased. Given a sufficient level of disease control, the lowest selection pressure on the double-resistant strain was often similar for the different resistance management strategies but could be lower for the mixture strategy when resistance to fungicides was partial.

Although this study involved winter wheat infected by $M$. graminicola as the host-pathogen system, the development of the canopy of different cereal species proceeds through similar stages and the life cycle of most fungal foliar pathogens of cereal crops consists of similar developmental stages. Therefore, the basic model structure should be applicable to other cereal-fungal pathogen systems. In this study, treatment strategies consisted of two fungicide sprays per growing season. At least two treatments are used for the control of M. graminicola on winter wheat in the United Kingdom but the number of sprays per growing season may vary between growing areas depending on the disease pressure, host resistance, and expected gain in yield by the use of fungicides. We hypothesize that the number of sprays per growing season does not affect the ranking of treatment strategies based on their usefulness for resistance management because the mixture strategy will always have the advantage over other strategies, in that it can control both single-resistant strains. However, more simulations would be required to test this hypothesis.

The analysis presented here has been limited to simulations representing (i) a fungal pathogen that produces ascospores which disperse between sets of fields, to initiate epidemics in the following season; (ii) the evolution of resistance during the selection phase rather than the stochastic processes during the emergence phase (28), when the densities of resistant strains are very low and strains may die out by random chance; (iii) substantial "step changes" in resistance, rather than a gradual shift in sensitivity, such as may be the case for polygenically controlled resistance (31); and (iv) a haploid pathogen where heterozygotes of intermediate sensitivity cannot exist (unlike for many invertebrate pest and weed species). However, these characteristics and circumstances are representative of many important combinations of pathogen species and MOA. In such cases, the findings reported here were consistent across a range of scenarios and suggest that the effective life of high-risk fungicides with differing MOA is likely to be maximized by applying them in a mixture.

\section{ACKNOWLEDGMENTS}

Funding for this research was provided by the Chemicals Regulation Directorate of the Health and Safety Executive, and the Department for Environment, Food and Rural Affairs of the United Kingdom. Rotham- sted Research receives support from the Biotechnology and Biological Sciences Research Council of the United Kingdom and by the Australian Grains Research and development Corporation.

\section{LITERATURE CITED}

1. Anonymous. 2010. FRAC recommendations for fungicide mixtures designed to delay resistance evolution. Fungicide Resistance Action Committee. http://www.frac.info/

2. Birch, C. P. D., and Shaw, M. W. 1997. When can reduced doses and pesticide mixtures delay the build-up of pesticide resistance? A mathematical model. J. Appl. Ecol. 34:1032-1042.

3. Bolton, N. J. E., and Smith, J. M. 1988. Strategies to combat fungicide resistance in barley powdery mildew. Pages 367-372 in: Proc. 1988 Brighton Crop Prot. Conf. Pests Dis. British Crop Protection Council, UK.

4. Brent, K. J., Carter, G. A., Hollomon, D. W., Hunter, T., Locke, T., and Proven, M. 1989. Factors affecting the build-up of fungicide resistance in powdery mildew in spring barley. Neth. J. Plant Pathol. 95 (Suppl.)1:3141.

5. Brent, K. J., and Hollomon, D. W. 2007. Fungicide resistance in crop pathogens: how can it be managed? FRAC Monogr. No. 1. Fungicide Resistance Action Committee. http://www.frac.info/

6. Bryson, R. J., Paveley, N. D., Clark, W. S., Sylvester-Bradley, R., and Scott, R. K. 1997. Use of in-field measurements of green leaf area and incident radiation to estimate the effects of yellow rust epidemics on the yield of winter wheat. Eur. J. Agron. 7:53-62.

7. Carnegie, S. F., Cameron, A. M., and Haddon, P. 2008. Effects of fungicide and rate of application on the development of isolates of Polyscytalum pustulans resistant to thiabendazole and on the control of skin spot. Potato Res. 51:113-129.

8. Carnegie, S. F., Cameron, A. M., Hide, G. A., and Hall, S. M. 1994. The occurrence of the thiabendazole-resistant isolates of Polyscytalum pustulans and Helminthosporium solanum on seed potato tubers in relation to fungicide treatment and storage. Plant Pathol. 43:961-971.

9. Dovas, C., Skylakakis, G., and Georgopoulos, S. G. 1976. Adaptability of benomyl-resistant population of Cercospora beticola in northern Greece. Phytopathology 66:1452-1456.

10. Forster, B., Chavaillaz, D., Steden, C., Radtke, W., Kasbohrer, M., and Kuhl, A. 1994. Influence of split application of fenpropimorph mixtures on disease control and on the sensitivity of Erysiphe graminis f. sp. tritici. Pages 331-335 in: Fungicide Resistance. British Crop Protection Council Monograph 60. S. Heaney, D. Slawson, D. W. Hollomon, M. Smith, P. E. Russell, and D. W. Parry, eds. British Crop Protection Council. http://www.frac.info/

11. Forster, B., and Staub, T. 1996. Basis for use strategies of anilinopyrimidine and phenylpyrrole fungicides against Botrytis cinerea. Crop Prot. 15:529-537.

12. Foulkes, M. J., Paveley, N. D., Worland, A., Welham, S. J., Thomas, J., and Snape, J. W. 2006. Major genetic changes in wheat with potential to affect disease resistance. Phytopathology 96:680-688.

13. Fraaije, B. A., Cools, H. J., Fountaine, J., Lovell, D. J., Motteram, J., West, J. S., and Lucas, J. A. 2005. Role of ascospores in further spread of QoI-resistant cytochrome b alleles (G143A) in field populations of Mycosphaerella graminicola. Phytopathology 95:933-941.

14. Hoare, F. A., Hunter, T., and Jordan, V. W. L. 1986. Influence of spray programs on development of fungicide resistance in the eyespot pathogen of wheat, Pseudocercosporella herpotrichoides. Plant Pathol. 35:506-511.

15. Hobbelen, P. H. F., Paveley, N. D., Fraaije, B. A., Lucas, J. A., and Van den Bosch, F. 2011. Derivation and validation of a model to predict selection for fungicide resistance. Plant Pathol. 60:304-313.

16. Hobbelen, P. H. F., Paveley, N. D., and van den Bosch, F. 2011. Delaying selection for fungicide insensitivity by mixing fungicides at a low and high risk of resistance development: A modelling analysis. Phytopathology 101:1224-1233.

17. Horsten, J. A. H. M. 1979. Acquired resistance to systemic fungicides of Septoria nodorum and Cercosporella herpotrichoides in cereals. Ph.D. thesis, Wageningen University, The Netherlands.

18. Hunter, T., Brent, K. J., and Carter, G. A. 1984. Effects of fungicide regimes on sensitivity and control of barley mildew. Pages 471-476 in: Proc. 1984 Br. Crop Prot. Conf. Pests Dis. British Crop Protection Council, UK.

19. Josepovits, G. 1989. A detailed model of the evolution of fungicide resistance for the optimization of spray applications. Crop Prot. 8:106-113.

20. Josepovits, G., and Dobrovolszky, A. 1985. A novel mathematical approach to the prevention of fungicide resistance. Pestic. Sci. 16:17-22.

21. Kable, P. F., and Jeffrey, H. 1980. Selection for tolerance in organisms exposed to sprays of biocide mixtures: A theoretical model. Phytopathology 70:8-12 
22. Köller, W., and Wilcox, W. F. 1999. Evaluation of tactics for managing resistance of Venturia inaequalis to sterol demethylation inhibitors. Plant Dis. 83:857-863.

23. Levy, Y., Benderly, M., Cohen, Y., Gisi, U., and Bassand, D. 1986. The joint action of fungicides in mixtures: Comparison of two methods for synergy calculation. EPPO Bull. 16:651-657.

24. Levy, Y., Levy, R., and Cohen, R. 1983. Build-up of a pathogen subpopulation resistant to a systemic fungicide under various control strategies: a flexible simulation model. Phytopathology 73:1475-1480.

25. Lockley, D., and Clark, W. S. 2005. Fungicide dose-response trials in wheat: the basis for choosing 'appropriate dose'. Project Report 373, Home-Grown Cereals Authority, United Kingdom.

26. Mavroeidi, V. I., and Shaw, M. W. 2006. Effects of fungicide dose and mixtures on selection for triazole resistance in Mycosphaerella graminicola under field conditions. Plant Pathol. 55:715-725.

27. Milgroom, M. G., and Fry, W. E. 1988. A simulation analysis of the epidemiological principles for fungicide resistance management in pathogen populations. Phytopathology 78:565-570.

28. Oxley, S. J. P., Burnett, F., Hunter, E. A., Fraaije, B. A., Cooke, L. R., Mercer, P. C., and Gilchrist, A. 2008. Understanding fungicide mixtures to control Rhynchosporium in barley and minimise resistance shifts. Project Report 436, Home-Grown Cereals Authority, United Kingdom.

29. Paveley, N. D., Blake, J., Gladders, P., and Cockerell, V. 2011. The HGCA Wheat Disease Management Guide. Home-Grown Cereals Authority, United Kingdom.

30. Sanders, P. L., Houser, W. J., Parish, P. J., and Cole, H. 1985. Reducedrate fungicide mixtures to delay fungicide resistance and to control selected turfgrass diseases. Plant Dis. 69:939-943.

31. Shaw, M. W. 1989. A model of the evolution of polygenically controlled fungicide resistance. Plant Pathol. 38:44-55.

32. Shaw, M. W. 1989. Independent actions of fungicides and its consequences for strategies to retard the evolution of fungicide resistance. Crop Prot. 8:405-411.
33. Shaw, M. W. 1993. Theoretical analysis of the effect of interacting activities on the rate of selection for combined resistance to fungicide mixtures. Crop Prot. 12:120-126.

34. Shaw, M. W. 2006. Is there such a thing as a fungicide resistance strategy? A modeller's perspective. Asp. Appl. Biol. 78:37-43.

35. Shaw, M. W., and Royle, D. J. 1989. Airborne inoculum as a major source of Septoria tritici (Mycosphaerella graminicola) infections in winter wheat crops in the UK. Plant Pathol. 38:35-43.

36. Shipton, W. A., Boyd, W. R. J., Rosielle, A. A., and Shearer, B. I. 1971. The common Septoria diseases of wheat. Bot. Rev. 37:231-262.

37. Skylakakis, G. 1981. Effects of alternating and mixing pesticides on the build-up of fungicide resistance. Phytopathology 71:1119-1121.

38. Taggart, P. J., Cooke, L. R., Mercer, P. C., and Shaw, M. W. 1998. Effects of fungicides used to control Rhynchosporium secalis where benzimidazole resistance is present. Crop Prot. 17:727-734.

39. Thornley, J. H. M., and Johnson, I. R. 1990. Plant and Crop Modelling. Clarendon Press, Oxford.

40. Thygesen, K., Jorgensen, L. N., Jensen, K. S., and Munk, L. 2009. Spatial and temporal impact of fungicide spray strategies on fungicide sensitivity of Mycosphaerella graminicola in winter wheat. Eur. J. Plant Pathol. 123:435-447.

41. van den Bosch, F., and Gilligan, C. A. 2008. Models of fungicide resistance dynamics. Annu. Rev. Phytopathol. 46:123-147.

42. van den Bosch, F., Paveley, N., Shaw, M., Hobbelen, P., and Oliver, R. 2011. The dose rate debate: does the risk of fungicide resistance increase or decrease with dose? Plant Pathol. 60:597-606.

43. Waggoner, P. E., and Berger, R. D. 1987. Defoliation, disease, and growth. Phytopathology 77:393-398.

44. Zadoks, J. C., Chang, T. T., and Konzak, C. F. 1974. Decimal code for growth stages of cereals. Weed Res. 14:415-421.

45. Zhang, C. Q., Zhang, Y., and Zhu, G. N. 2008. The mixture of kresoximmethyl and boscalid, an excellent alternative controlling grey mould caused by Botrytis cinerea. Ann. Appl. Biol. 153:205-213. 